$9 / 24979+1$

SAND97-8235 • UC-404 Unlimited Release

Printed February 1997

\title{
Development of a Process Simulation Capability for the Formation of Titanium Nitride Diffusion Barriers
}

M.D. Allendorf, A. Arsenlis, R. Bastasz, M.E. Colvin, G. Evans, G. Germann, C.L. Janssen, R.S. Larson, C.F. Melius, T.H. Osterheld, D.A. Outka, M.L. Schulberg, P. Ho, I.M.B. Nielsen

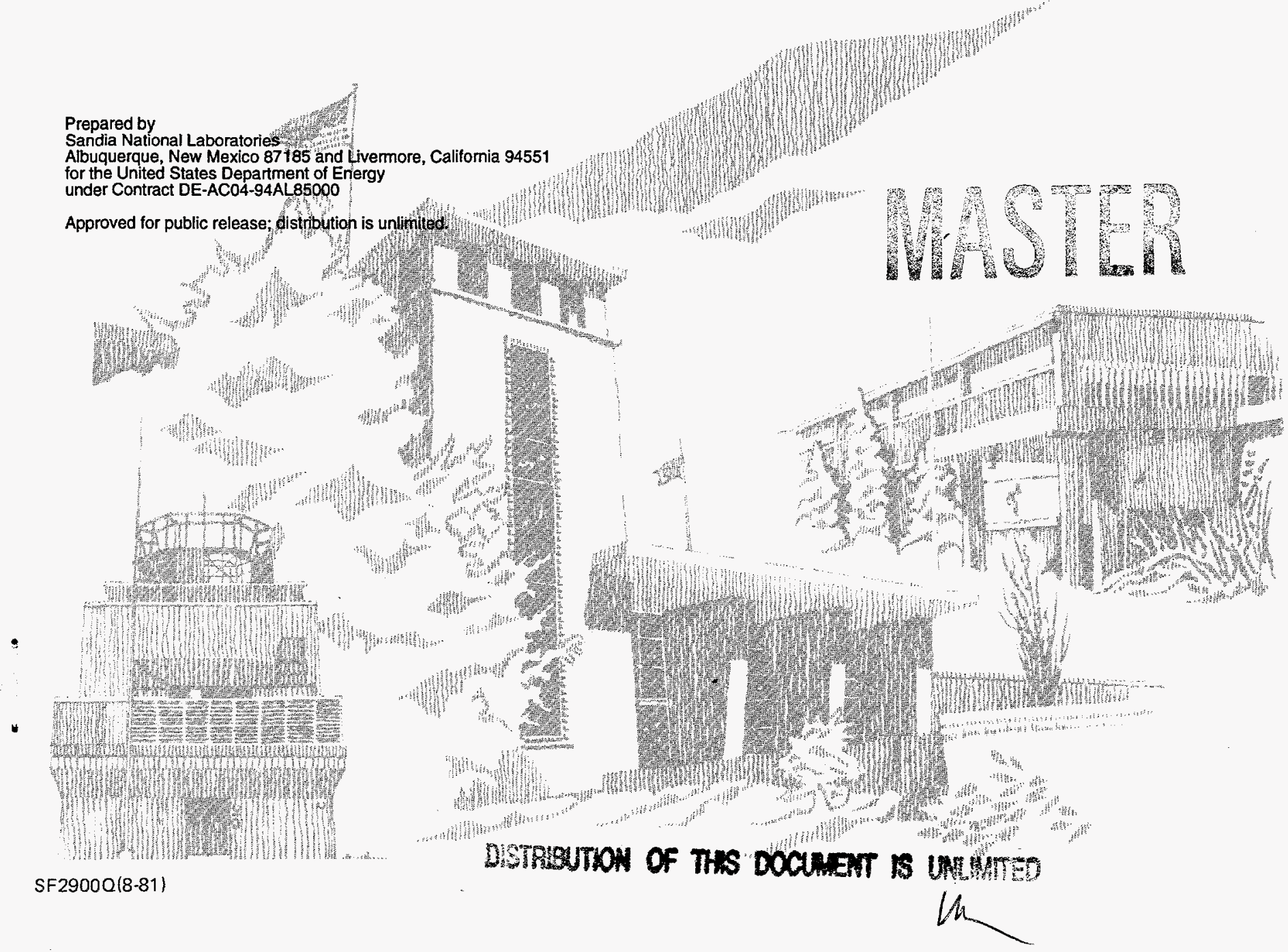


Issued by Sandia National Laboratories, operated for the United States Department of Energy by Sandia Corporation.

NOTICE: This report was prepared as an account of work sponsored by an agency of the United States Government. Neither the United States Government nor any agency thereof, nor any of their employees, nor any of the contractors, subcontractors, or their employees, makes any warranty, express or implied, or assumes any legal liability or responsibility for the accuracy, completeness, or usefulness of any information, apparatus, product, or process disclosed, or represents that its use would not infringe privately owned rights. Reference herein to any specific commercial product, process, or service by trade name, trademark, manufacturer, or otherwise, does not necessarily constitute or imply its endorsement, recommendation, or favoring by the United States Government, any agency thereof or any of their contractors or subcontractors. The views and opinions expressed herein do not necessarily state or reflect those of the United States Government, any agency thereof, or any of their contractors or subcontractors.

This report has been reproduced from the best available copy.

Available to DOE and DOE contractors from:

Office of Scientific and Technical Information

P.O. Box 62

Oak Ridge TN 37831

Prices available from (615) 576-8401, FTS 626-8401.

Available to the public from:

National Technical Information Service

U.S. Department of Commerce

5285 Port Royal Rd.

Springfield, VA 22161 


\section{DISCLAIMER}

This report was prepared as an account of work sponsored by an agency of the United States Government. Neither the United States Government nor any agency thereof, nor any of their employees, make any warranty, express or implied, or assumes any legal liability or responsibility for the accuracy, completeness, or usefulness of any information, apparatus, product, or process disclosed, or represents that its use would not infringe privately owned rights. Reference herein to any specific commercial product, process, or service by trade name, trademark, manufacturer, or otherwise does not necessarily constitute or imply its endorsement, recommendation, or favoring by the United States Government or any agency thereof. The views and opinions of authors expressed herein do not necessarily state or reflect those of the United States Government or any agency thereof. 


\section{DISCLAMMER}

Portions of this document may be illegible in electronic image products. Images are produced from the best available original document. 
SAND97-8235

Unlimited Release

Printed Febraury 1997

\title{
Development of a Process Simulation Capability for the Formation of Titanium Nitride Diffusion Barriers
}

\author{
Final Report \\ Laboratory Research and Development Project
}

\author{
Mark D. Allendorf, ${ }^{*}$ A. Arsenlis, R. Bastasz, M. E. Colvin, G. Evans, G. Germann, ${ }^{\dagger}$ \\ C. L. Janssen, R. S. Larson, C. F. Melius, T. H. Osterheld, $\S$ \\ D. A. Outka, M. L. Schulberg, \\ Sandia National Laboratories \\ Livermore, CA 94551-0969 \\ P. Ho \\ Sandia National Laboratories \\ Albuquerque, NM 87185 \\ and \\ I. M. B. Nielsen \\ Department of Chemistry \\ Stanford University \\ Stanford, CA 94305
}

\begin{abstract}
Titanium nitride (TiN) films deposited by chemical vapor deposition (CVD) techniques are of interest for a wide range of commercial applications. In this report, we describe a mechanism that predicts TiN film growth rates from $\mathrm{TiCl} / \mathrm{NH}_{3}$ mixtures as a function of process parameters, including inlet reactant concentrations, substrate temperatures, reactor pressures, and total gas flow rates. Model predictions were verified by comparison with the results of TiN deposition experiments in the literature and with measurements made in a new stagnation-flow reactor developed for the purpose of testing deposition mechanisms such as this. In addition, we describe $a b$ initio calculations that predict thermodynamic properties for titanium-containing compounds. The results of calculations using Møller-Plesset perturbation theory, density functional theory, and coupled cluster theory are encouraging and suggest that these methods can be used to estimate thermodynamic data that are essential for the development of CVD models involving transitionmetal compounds. Finally, measurements of the adsorption and desorption kinetics of $\mathrm{NH}_{3}$ on TiN films using temperature-programmed desorption are described and their relevance to TiN CVD and mechanism development are discussed.

* Combustion Research Facility

$\dagger$ Present address: Energia Inc., P.O. Box 470, Princeton, NH 08542

$\S$ Present address: Applied Materials, Inc. Mail Stop 1510, 3111 Coronado Drive, Santa Clara, CA 95054

Il Prsent address: Lam Research Corp., Mail Stop CA3, 4650 Cushing Parkway, Fremont, CA 94538

@ Present address: Varian Associates, 3075 Hansen Way, MS K-455, Palo Alto, CA 94304
\end{abstract}




\section{Introduction}

As the dimensions of integrated circuits shrink with each new generation, reliable electrical contact between these devices becomes ever more important. Currently, electrical contact between the device and the "wire" is made through a barrier layer, typically composed of sputter-deposited titanium and titanium-tungsten alloys. This layer limits interdiffusion between the metal (typically an aluminum/copper/silicon alloy) and the silicon device while simultaneously providing good electrical contact. Thus, diffusion barriers are a critical enabling technology required in both current and future devices. TiN is also used to protect previously deposited functionalities from etching by $\mathrm{WF}_{6},{ }^{1}$ as an adhesion or nucleation layer between intermetal-level dielectrics and tungsten deposited by chemical vapor deposition (CVD), ${ }^{2}$ as a gate electrode in MOS integrated circuits, ${ }^{3}$ and as an antireflection layer during lithography. In addition to these applications in the microelectronics industry, TiN is used as a wear-resistant coating for machine tools, ${ }^{4}$ and may be used to improve the energy efficiency of glass, due to its optical properties in the visible and IR regions of the spectrum.

Like titanium, TiN can be deposited via sputtering; unfortunately, the ability of sputtering to provide conformal deposition, especially in high aspect-ratio vias and contacts, is limited. In contrast, CVD processes have the potential to provide excellent conformal deposition of TiN. Unfortunately, existing TiN CVD methods suffer from a number of drawbacks. Mixtures of titanium tetrachloride $\left(\mathrm{TiCl}_{4}\right)$ and ammonia can be used, but require relatively high temperatures $(>773 \mathrm{~K})$ to reduce the residual chlorine content of the film to less than $5 \% .5$ These temperatures are too high for use in multilevel metallization schemes, but can be acceptable in other applications. ${ }^{6}$ Recently, metal-organic (MO) compounds, such as tetrakis-(dimethylamido)titanium (TDMAT) have been shown to be effective precursors for deposition of TiN at much lower temperatures. ${ }^{7}$ The metal-organic compound is sometimes mixed with ammonia to achieve highpurity (i.e., low carbon) films with deposition at temperatures as low as $473 \mathrm{~K} .{ }^{8}$ Two significant technical obstacles must be surmounted before efficient MOCVD processes can be developed, however. First, the step coverage, which is worse than that obtained from inorganic precursors, must be improved. Second, impurity levels must be reduced, since films contaminated with even a few percent of carbon (apparently incorporated as titanium carbide) have resistivities that are unacceptable for barrier-layer applications.

Experimental studies of TiN CVD performed recently indicate that chemical reactions in the gas-phase may have a major influence on the ability of the process to produce good step coverage and high-purity films. For example, investigations using infrared spectroscopy demonstrate that TDMAT reacts with ammonia at temperatures as low as $323 \mathrm{~K}$ to produce dimethylamine. ${ }^{9}$ Such reactions may generate species that are more reactive with the surface than the original precursor, so that deposition is not rate-limited by surface kinetics, leading to poor step coverage. The identity of these intermediates and the kinetics of their decomposition (and/or that of the original precursor) on the surface likely determine the concentration of impurities such as carbon or chlorine. Novel solutions to this problem have been proposed, such as the use of plasmas upstream of the precursor injection point to produce hydrogen or nitrogen atoms, which then mix with the precursor. ${ }^{1}$ In any case, it is clear that the details of the surface and gas-phase reaction kinetics must be known in order to develop reliable, reproducible methods for TiN CVD.

The objective of this project is to characterize the chemistry of TiN CVD and use this information to develop a first-generation model that can predict TiN deposition rates as a function of reactor parameters (temperature, pressure, concentration, and flow rates). Models of this type can then be used to evaluate the effects of reactor design and operating conditions on deposition rate, step coverage, and deposit composition. With sufficient knowledge of the chemical reactions that occur, the performance of novel TiN precursors can also be investigated. Of the several precursor systems available, the inorganic compounds $\mathrm{TiCl}_{4}$ and $\mathrm{NH}_{3}$ were chosen for this investigation because, first, the chemistry of deposition from these precursors is likely to be 
considerably simpler than that involved in MOCVD, and second, these compounds are small enough that $a b$ initio quantum chemistry methods can be used to predict thermochemical data needed for model development. These relatively simple inorganic compounds are a useful starting point for treating more complex chemistries, such as TDMAT/NH3 mixtures. Finally, there is renewed interest in the use of these precursors with the recent development of a TiN deposition tool by MRC Corp. ${ }^{6}$

This report describes the most significant results of this two-year project, which included the following elements: 1) application of $a b$ initio methods to titanium-containing systems, for the purpose of predicting thermochemical properties; 2) experimental investigations of the interaction of ammonia with TiN surfaces; 3 ) development of a model that predicts TiN deposition rates from $\mathrm{TiCl}_{4} / \mathrm{NH}_{3}$ mixtures; 4) construction of a stagnation-flow reactor to obtain data for comparison with model predictions; and 5) deposition experiments. More detailed discussions of each of these topics can be found in the various publications that resulted from this work. [Allendorf, 1995 \#3; Allendorf, 1997 \#5; Larson, 1996 \#2; Schulberg, 1995 \#4; Schulberg, 1996 \#1; Mori, 1997 \#6]

\section{Ab initio Calculations of Thermodynamic Properties of Titanium-Containing Compounds}

Although experimental investigations by several groups suggest that gas-phase reactions may play a role in TiN CVD from $\mathrm{TiCl}_{4}$ and $\mathrm{NH}_{3}{ }^{16-18}$ little is known about this chemistry. In particular, relevant thermochemical data (heats of formation, enthalpies, and heat capacities) are unavailable for all but a few titanium compounds. The JANAF Tables ${ }^{19}$ include data for the species in the $\mathrm{TiCl}_{\mathrm{x}}$ series $(\mathrm{x}=0-4)$ and recently Hildenbrand ${ }^{20}$ reported heats of formation for titanium sub-chlorides $\left(\mathrm{TiCl}_{\mathrm{n}}, \mathrm{n}=1-3\right)$. Since a more in-depth understanding of the $\mathrm{TiCl}_{4} / \mathrm{NH}_{3}$ gas-phase chemistry is necessary before accurate TiN CVD process models can be developed, a first step must be to expand the base of available thermochemical data.

The objective of this work is to establish theoretical methods for predicting the thermochemistry of titanium-containing compounds. In this section, we report bond dissociation enthalpies (BDEs) and atomization energies $\left(\Delta H^{\circ}\right.$ atom), from which heats of formation can be derived, predicted by $a b$ initio electronic structure calculations for $\mathrm{TiCl}_{n}(\mathrm{n}=1-4)$ and the complex $\mathrm{TiCl}_{4}: \mathrm{NH}_{3}$. Results are also reported for $\mathrm{Ti}\left(\mathrm{NH}_{2}\right)_{\mathrm{n}}(\mathrm{n}=1-4)$ compounds, which are analogues for more complex metal-organic precursors, such as $\mathrm{Ti}\left(\mathrm{N}\left(\mathrm{CH}_{3}\right)_{2}\right)_{4}$ (TDMAT). Finally, we discuss the energetics of gas-phase chemical reactions that might occur when $\mathrm{TiCl}_{4}$ and $\mathrm{NH}_{3}$ are used as precursors for TiN CVD.

\section{A. Theoretical Methods}

Electronic energies were predicted using three $a b$ initio methods: Møller-Plesset (MP) perturbation theory, density functional (DFT) theory, and coupled cluster (CC) theory. Each method has been described in detail elsewhere, so we present only a short description here. In all cases, the energies reported are for $0 \mathrm{~K}$ and were corrected for the zero-point energy.

Electronic structure calculations using MP theory ${ }^{21}$ were performed using the Gaussian 92 quantum chemistry code. 22 Equilibrium geometries and harmonic vibrational frequencies were obtained at the Hartree-Fock level of theory using the supplemented Wachters basis set of Hood et al. 23,24 on $\mathrm{Ti}$ and a $6-31 \mathrm{G}^{*}$ basis set on $\mathrm{Cl}, \mathrm{N}$, and $\mathrm{H}$. To determine atomization enthalpies and thus heats of formation, the effects of electron correlation were included by performing singlepoint calculations, using second, third, and fourth-order MP theory at the optimized geometries. MP4(SDTQ)/6-31G** calculations (fourth-order perturbation theory with single, double, triple and quadruple substitutions using the Wachters and $6-31 \mathrm{G}^{* *}$ basis sets) were performed to obtain the final electronic energies. 
$\mathrm{TiCl}_{n}$ electronic energies were also predicted from $\mathrm{CC}$ calculations with single and double excitations and a perturbative triples correction (CCSD(T)). [Raghavachari, 1989 \#63; Scuseria, 1991 \#64] All CC wave functions were based on RHF reference wavefunctions. Basis sets used to describe titanium were the supplemented Wachter's basis and Bauschlicher and Taylor's ANO basis set. ${ }^{27}$ Chlorine basis sets included a DZP basis set ${ }^{28}$ with a polarization function exponent of 0.75 and the aug-cc-pVDZ basis set. [Woon, 1993 \#65] Geometries were optimized at the CCSD level of theory using the aug-cc-pVDZ basis set on chlorine and the Wachters basis set of Hood et al. ${ }^{23,24}$ on $\mathrm{Ti}$.

DFT is an inexpensive $a b$ initio method in which the exchange and correlation energy are determined from a functional of the electron density. ${ }^{29}$ This functional may include parameters derived empirically or from accurate simulations of idealized systems such as an electron gas. The predictions of DFT are often surprisingly accurate--comparable, in some cases, to CCSD(T). However, the lack of a systematic path to improved accuracy (via successively higher levels of theory) makes DFT unattractive as a primary source of electronic energies. We applied a popular DFT exchange-correlation functional (DFT(BLYP)), which combines Becke's non-local exchange ${ }^{25}$ with the non-local correlation functional of Lee, Yang, and Parr. ${ }^{26}$ The optimized geometries obtained from the MP calculations were used in these calculations.

\section{B . Results}

Because MP successfully predicts the thermochemistry of first- and second-row compounds, [Allendorf, 1995 \#61; Melius, 1990 \#62] this was the method of choice for our initial effort to predict electronic energies for titanium-containing species. Results of these calculations are given in Tables I and II. Five different levels of theory are shown, proceeding from the lowest to the highest: Hartree-Fock (HF), second- (MP2) and third-order (MP3) perturbation theory, and fourth-order perturbation with single, double, and quadruple excitations (MP4(SDQ)) and single, double, triple, and quadruple excitations (MP4(SDTQ)). It is evident that the HF results, which do not include the effects of electron correlation, are quite different from any of the MP predictions, demonstrating that correlation is very important in these molecules. For most of the compounds, the MP expansion converges to an approximately constant value as the level of theory increases. Exceptions to this are $\mathrm{TiCl}_{4}$ and $\mathrm{Ti}\left(\mathrm{NH}_{2}\right)_{4} \mathrm{BDEs}$, neither of which converges to a constant value. Instead, the predicted BDEs oscillate from one level of theory to the next. A general convergence trend can be observed: As the number of ligands on the titanium atom increases from one to four, the magnitude of the variation in the predicted $\mathrm{BDE}$ increases. The variation is also larger for $\mathrm{Cl}$ than for $\mathrm{NH}_{2}$. The likely cause of this behavior is mixing of excited electronic configurations with the reference wave function used for the ground state, which evidently becomes more significant as the number of ligands increases.

Better convergence behavior is expected from the $\mathrm{CC}$ calculations, which can more accurately predict electronic energies for compounds where multiple electronic configurations are important. Results of these calculations for $\mathrm{TiCl}_{\mathrm{n}}$ compounds are given in Table I for the highest level of theory used, $\operatorname{CCSD}(\mathrm{T})$. In contrast with MP, the $C C$ calculations converged to a constant value with increasing level of theory for all four $\mathrm{TiCl}_{n}$ compounds (results not shown), suggesting that an accurate value (within a systematic error) has been achieved. In addition, calculations using progressively larger basis sets also converged, giving confidence that the basis sets used are adequate. The resulting BDEs are substantially different from the MP4(SDTQ) predictions and $\Delta H^{\circ}$ atom is consistently lower, even for the cases where the MP series was well converged. Unfortunately, CCSD(T) is computationally intensive for these molecules and requires some molecular symmetry to obtain manageable computation times. Thus, it was impractical to calculate $\mathrm{BDEs}$ using the larger basis sets for the titanium amines, which contain minimal symmetry. 
Given the large differences between the MP and CC predictions, a third method, DFT(BLYP), was applied to provide confirmation of the CCSD(T) results. As shown in Tables I and II, there is no consistent agreement between the BDEs predicted by BLYP and MP (for the $\mathrm{TiCl}_{\mathrm{n}}$ species, a complete set of BDEs could not be obtained because the calculation of the $\mathrm{TiCl}$ electronic energy did not converge). However, the values of $\Delta H^{\circ}$ atom predicted by BLYP are 24-34 kcal mol-1 smaller than those predicted by MP, as was the case for the CC results. Overall, therefore, these limited BLYP results are in better agreement with the CCSD(T) predictions than those of MP. It should be noted, however, that DFT exchange-correlation functionals other than BLYP can lead to widely varying results. For example, $\mathrm{TiCl}_{4}$ atomization energies of $481.1,317.2$, and $393.8 \mathrm{kcal}$ $\mathrm{mol}^{-1}$ were obtained from the local density approximation, BLYP with $50 \% \mathrm{HF}$ exchange, and Becke exchange with Perdue's 986 correlation functional, respectively.

Table I. Predicted $\mathrm{BDE}$ and $\Delta H^{\circ}$ atom (in parenthesis) for $\mathrm{TiCl}_{\mathrm{n}}$ species, in $\mathrm{kcal} \mathrm{mol}^{-1}$.

\begin{tabular}{|c|c|c|c|c|c|c|c|}
\hline Bond & $\mathrm{HF}$ & MP2 & MP3 & $\begin{array}{l}\text { MP4 } \\
\text { (SDQ) }\end{array}$ & $\begin{array}{c}\text { MP4 } \\
\text { (SDTQ) }\end{array}$ & $\mathrm{CCSD}(\mathrm{T})$ & $\begin{array}{c}\text { DFT } \\
\text { (BLYP) }\end{array}$ \\
\hline $\mathrm{Cl}_{3} \mathrm{Ti}-\mathrm{Cl}$ & 17.8 & 88.0 & 59.4 & 88.6 & $\begin{array}{r}120.2 \\
(476.0)\end{array}$ & $\begin{array}{r}81.1 \\
(384.1)\end{array}$ & $\begin{array}{r}92.1 \\
(415.3)\end{array}$ \\
\hline $\mathrm{Cl}_{2} \mathrm{Ti}-\mathrm{Cl}$ & 55.0 & 97.9 & 90.0 & 95.1 & $\begin{array}{r}104.5 \\
(355.8)\end{array}$ & $\begin{array}{r}96.2 \\
(303.0)\end{array}$ & $\begin{array}{r}108.7 \\
(323.2)\end{array}$ \\
\hline ClTi-Cl & 81.7 & 102.8 & 100.6 & 100.0 & $\begin{array}{r}101.3 \\
(251.3)\end{array}$ & $\begin{array}{r}119.8 \\
(206.8)\end{array}$ & (214.5) \\
\hline Ti-Cl & 144.2 & 155.7 & 150.8 & 148.9 & $\begin{array}{r}150.0 \\
(150.0)\end{array}$ & $\begin{array}{r}87.0 \\
(87.0)\end{array}$ & - a \\
\hline
\end{tabular}

a $\mathrm{TiCl}$ did not converge.

Experimental measurements of the Ti-Cl BDE and $\mathrm{TiCl}_{\mathrm{n}} \Delta H^{\circ}$ atom are given in Table III for comparison with the ab initio results in Table I. Several trends are evident. First, MP4(SDTQ) consistently overpredicts $\Delta H^{\circ}$ atom by $25-65 \mathrm{kcal} \mathrm{mol}^{-1}$, with no trend evident with respect to the number of $\mathrm{Ti}-\mathrm{Cl}$ bonds. There is also wide disagreement with three of the four BDEs obtained from the experimental data, although the magnitude and sign of the difference varies. Second, in contrast with the MP results, the CCSD(T) predictions of both $\mathrm{BDE}$ and $\Delta H^{\circ}$ atom are consistently low with respect to both sets of experimental data. However, $\Delta H^{\circ}$ atom is within $28 \mathrm{kcal}^{\mathrm{mol}} \mathbf{1}^{-1}$ of the experimental values and the amount decreases with decreasing number of $\mathrm{Ti}-\mathrm{Cl}$ bonds, suggesting that a systematic error exists with respect to the Ti-Cl bond energy. Finally, the BLYP predictions of $\Delta H^{3}$ atom are within the range of values defined by the experimental error bars for $\mathrm{TiCl}_{2}, \mathrm{TiCl}_{3}$, and $\mathrm{TiCl}_{4}$. The two BDEs predicted by $\mathrm{BLYP}$ are within $15 \mathrm{kcal} \mathrm{mol}-1$ of the experimental values. Thus, of the three methods, the limited predictions obtained from the DFT calculations are the most consistent with the available experimental data.

The trend in the $\operatorname{CSSD}(\mathrm{T})$ results with respect to the experimental data and the convergence trends of the CC calculations suggest that the CCSD(T) predictions represent a lower limit for the $\Delta H^{\circ}$ atom, with the difference between the predicted and measured values due to a systematic error caused by the finite size of the basis set used. If we assume that the magnitude of this error is proportional to the number of $\mathrm{Ti}-\mathrm{Cl}$ bonds, then a bond-additivity correction (BAC) to $\Delta H^{\circ}$ atom can be defined by Equation (1):

$$
\mathrm{BAC}=\left[\Delta H^{\circ} \text { atom }(\exp )-\Delta H^{\circ} \text { atom }(\operatorname{CCSD}(\mathrm{T}))\right] / n
$$


Table II. Predicted BDE and $\Delta H^{\circ}$ atom for $\mathrm{Ti}\left(\mathrm{NH}_{2}\right)_{\mathrm{n}}$ species, in $\mathrm{kcal} \mathrm{mol}{ }^{-1}$.

\begin{tabular}{|c|c|c|c|c|c|c|c|c|}
\hline \multirow[b]{2}{*}{ Bond } & \multirow[t]{2}{*}{$\mathrm{HF}$} & \multirow[t]{2}{*}{ MP2 } & \multirow[t]{2}{*}{ MP3 } & \multirow{2}{*}{$\begin{array}{l}\text { MP4 } \\
\text { (SDQ) }\end{array}$} & \multicolumn{2}{|c|}{ MP4 (SDTQ) } & \multicolumn{2}{|c|}{ DFT (BLYP) } \\
\hline & & & & & $\overline{\mathrm{BDE}}$ & $\Delta H_{\mathrm{atom}}^{\circ}$ & $\overline{\mathrm{BDE}}$ & $\Delta H_{\text {atom }}^{\circ}$ \\
\hline$\left(\mathrm{NH}_{2}\right)_{3} \mathrm{Ti}-\mathrm{NH}_{2}$ & 28.5 & 86.2 & 69.1 & 78.3 & 93.5 & 400.6 & 86.1 & 365.4 \\
\hline$\left(\mathrm{NH}_{2}\right)_{2} \mathrm{Ti}-\mathrm{NH}_{2}$ & 55.6 & 92.9 & 84.4 & 87.0 & 92.2 & 307.1 & 100.7 & 279.3 \\
\hline$\left(\mathrm{NH}_{2}\right) \mathrm{Ti}-\mathrm{NH}_{2}$ & 60.5 & 97.7 & 92.3 & 93.4 & 96.3 & 214.9 & 93.7 & 178.5 \\
\hline $\mathrm{Ti}-\mathrm{NH}_{2}$ & 101.2 & 125.4 & 117.0 & 116.5 & 118.6 & 118.6 & 84.8 & 84.8 \\
\hline $\mathrm{Cl}_{4} \mathrm{Ti}-\mathrm{NH}_{3}$ & 17.2 & 17.1 & 19.5 & 15.2 & 12.1 & & 17.0 & \\
\hline$\stackrel{\mathrm{Cl}_{4} \mathrm{TiNH}_{3} \rightarrow}{\rightarrow}$ & $24.6^{\mathrm{a}}$ & $29.8^{\mathrm{a}}$ & $26.4^{\mathrm{a}}$ & $32.1^{\mathrm{a}}$ & $37.1^{\mathrm{a}}$ & & $24.5^{\circ}$ & \\
\hline
\end{tabular}

a Enthalpy of reaction.

where $n$ is the number of $\mathrm{Ti}-\mathrm{Cl}$ bonds. Performing this calculation using the experimental atomization energies in Table III and the CCSD(T) predictions in Table I for $n=2-4$ yields a BAC ranging from 5.4 to $10.6 \mathrm{kcal} \mathrm{mol}^{-1}$. This BAC mol-1 is then added to the CCSD(T) results in Table I once for each $\mathrm{Ti}-\mathrm{Cl}$ bond present in the compound; for example, a total correction ranging from 10.8 to $21.2 \mathrm{kcal} \mathrm{mol}^{-1}$ is added to the $\mathrm{BDE}$ and $\Delta H^{\circ}$ atom for $\mathrm{TiCl}_{2}$. Applying this correction to the CCSD(T) predictions in Table I yields the BAC-CCSD(T) values shown in Table III. The corrected values compare well with both sets of experimental values. They also agree reasonably well with the DFT(BLYP) predictions in Table I.

Table III. Comparison of the bond-additivity-corrected CCSD(T) predictions of the Ti-Cl BDE $\left(\mathrm{kcal} \mathrm{mol}^{-1}\right)$ with available experimental values.

\begin{tabular}{|l|rr|rr|rr|}
\hline & \multicolumn{2}{|c|}{ BAC-CCSD(T) } & \multicolumn{2}{c|}{ JANAF Tables $^{\mathrm{a}}$} & \multicolumn{2}{c|}{ Other Experiments } \\
\cline { 2 - 7 } Bond & \multicolumn{1}{|c|}{$\mathrm{BDE}$} & \multicolumn{1}{|c|}{$\Delta H_{\text {atom }}^{\circ}$} & \multicolumn{1}{c|}{$\mathrm{BDE}$} & \multicolumn{1}{c|}{$\Delta H_{\text {atom }}^{\circ}$} & \multicolumn{1}{c|}{$\mathrm{BDE}$} & $\Delta H_{\text {atom }}^{\circ}$ \\
\hline $\mathrm{Cl}_{3} \mathrm{Ti}-\mathrm{Cl}$ & $86.5-91.7$ & $405.7-426.5$ & $82.5 \pm 2.4$ & $411.6 \pm 4.9$ & $92.8^{\mathrm{b}}$ & $411.9 \pm 4.9^{\mathrm{b}}$ \\
$\mathrm{Cl}_{2} \mathrm{Ti}-\mathrm{Cl}$ & $101.6-106.8$ & $319.2-334.8$ & $101.2 \pm 4.5$ & $329.1 \pm 5.5$ & $100.9 \mathrm{~b}$ & $319.1 \pm 8.3^{\mathrm{b}}$ \\
$\mathrm{ClTi}-\mathrm{Cl}$ & $125.2-130.4$ & $217.6-228.0$ & $122.6 \pm 13.0$ & $227.9 \pm 7.0$ & $121.3^{\mathrm{b}}$ & $218.2 \pm 7.5^{\mathrm{b}}$ \\
$\mathrm{Ti}-\mathrm{Cl}$ & $92.4-97.6$ & $92.4-97.6$ & $105.3 \pm 14.0$ & $105.3 \pm 14.0$ & $96.9 \mathrm{~b}$ & $96.9 \pm 6.5^{\mathrm{b}}$ \\
\hline
\end{tabular}

a Ref. [Chase, 1985 \#14]. b Ref. [Hildenbrand, 1996 \#15].

\section{Energetics of Gas-Phase Reactions}

The predicted BDEs discussed above allow several qualitative observations to be made regarding the importance of gas-phase chemistry in the CVD of TiN. First, it is clear that the $\mathrm{TiCl}_{4}$ $\mathrm{BDE}$ is too large for unimolecular decomposition $\left(\mathrm{TiCl}_{4} \rightarrow \mathrm{TiCl}_{3}+\mathrm{Cl}\right)$ to be fast at the temperatures typical of TiN CVD $(723-973 \mathrm{~K})$ from $\mathrm{TiCl}_{4}$. Assuming that the reaction is in its high-pressure limit at atmospheric pressure and an Arrhenius prefactor of $10^{16} \mathrm{sec}^{-1}$, both of which are reasonable for these molecules, the reaction rate will not be faster than $1 \mathrm{sec}^{-1}$ for temperatures below $1253 \mathrm{~K}$. This result is supported by the flow-reactor measurements discussed above. A similar conclusion can be drawn with respect to $\mathrm{Ti}\left(\mathrm{NH}_{2}\right)_{4}$, with a BDE predicted by BLYP of $86 \mathrm{kcal} \mathrm{mol}^{-1}$. If the bonding in metal-organic precursors such as TDMAT, for which deposition temperatures are typically less than $723 \mathrm{~K}$, is similar to that in $\mathrm{Ti}\left(\mathrm{NH}_{2}\right)_{4}$, then unimolecular decomposition in the metal organic systems should not be significant either.

A second observation to be made is that the calculations, in agreement with experiment, 16 predict that $\mathrm{TiCl}_{4}$ and $\mathrm{NH}_{3}$ react at room temperature to form a stable complex: 


$$
\mathrm{TiCl}_{4}+\mathrm{NH}_{3} \leftrightarrow \mathrm{Cl}_{4} \mathrm{Ti}_{\mathrm{NH}} \mathrm{NH}_{3}
$$

The strength of the Ti-N bond in this complex is predicted by BLYP to be $17 \mathrm{kcal} \mathrm{mol}^{-1}$ (Table I). This weak bond indicates that the compound will decompose into $\mathrm{TiCl}_{4}$ and $\mathrm{NH}_{3}$ at relatively low temperatures. Experiments have shown that formation of the $\mathrm{Cl}_{4} \mathrm{Ti}: \mathrm{NH}_{3}$ precipitate is not observed at temperatures above $523 \mathrm{~K},{ }^{16}$ suggesting that its decomposition to $\mathrm{TiCl}_{4}$ and $\mathrm{NH}_{3}$ is significant above this temperature.

Finally, the energetics of $\mathrm{HCl}$ elimination from $\mathrm{Cl}_{4} \mathrm{Ti}_{\mathrm{NH}}$ (Reaction (3)) predicted by BLYP (Table II) provide insight into the importance of this reaction under CVD conditions.

$$
\mathrm{Cl}_{4} \mathrm{Ti}: \mathrm{NH}_{3} \leftrightarrow \mathrm{Cl}_{3} \mathrm{TiNH}_{2}+\mathrm{HCl}
$$

BLYP predicts that the reaction is endothermic by only $20.0 \mathrm{kcal} \mathrm{mol}^{-1}$, suggesting that the rate could be significant at CVD temperatures. However, the transition state for Reaction (3) is more constrained than that of Reaction (2), leading to a much smaller (as much as two orders of magnitude) Arrhenius pre-exponential factor. Thus, Reaction (3) will be considerably slower than Reaction (-2). This analysis suggests that the concentration of $\mathrm{Cl}_{3} \mathrm{TiNH}_{2}$ will be low and that $\mathrm{TiCl}_{4}$ and $\mathrm{NH}_{3}$ will be the primary species interacting with the surface. Since, however, both the forward and reverse rates of Reaction (2). will be fast relative to Reaction (3), Reaction (2) may be at equilibrium under CVD conditions. If this is so, the rate of Reaction (3), and thus, the amount of $\mathrm{Cl}_{3} \mathrm{TiNH}_{2}$ formed, will depend on the equilibrium constant for Reaction (2). We are performing additional calculations to provide a quantitative estimate of the relative amounts of $\mathrm{Cl}_{3} \mathrm{TiNH}_{2}$ and $\mathrm{Cl}_{4} \mathrm{Ti}: \mathrm{NH}_{3}$ formed.

\section{Conclusions}

Several conclusions can be drawn from this work. First, poor convergence behavior is exhibited by closed-shell titanium compounds (TiX 4$)$, in calculations of the electronic energy using MP theory. The highest levels of theory applied in this study, MP4(SDTQ) and CCSD(T), yield BDEs for $\mathrm{TiCl}_{4}$ that differ by nearly $40 \mathrm{kcal} \mathrm{mol}^{-1}$. Second and somewhat surprisingly, of the three methods used, the predictions of DFT(BLYP) display the best agreement with experimental results, suggesting that this method should be explored further. However, the CCSD(T) predictions, which are expected to be the most reliable, can be brought into agreement with the available experimental data if bond-additivity corrections are applied. Finally, the energetics of gas-phase reactions between $\mathrm{TiCl}_{4}$ and $\mathrm{NH}_{3}$ are consistent with experimental observations concerning the formation of the $\mathrm{Cl}_{4} \mathrm{Ti}: \mathrm{NH}_{3}$ complex.

\section{The Interaction of Ammonia ( $\left.\mathrm{NH}_{3}\right)$ With TiN Surfaces}

Excess $\mathrm{NH}_{3}$ is usually the nitrogen source for inorganic deposition processes. In the case of the metalorganic precursors, an additional nitrogen-containing reactant is not stoichiometrically required; however, an excess of $\mathrm{NH}_{3}$ is necessary to produce high-purity, low-resistivity films. ${ }^{32}$ Also, for TDMAT, it has been shown ${ }^{33}$ that when $\mathrm{NH}_{3}$ is present, the nitrogen in the film comes from $\mathrm{NH}_{3}$ and not from the metalorganic compound. The overall deposition reaction is then the same in all cases:

$$
6 \mathrm{TiX}_{4}+8 \mathrm{NH}_{3} \rightarrow 6 \mathrm{TiN}+24 \mathrm{HX}+\mathrm{N}_{2} \quad \mathrm{X}=\mathrm{Cl}, \mathrm{NMe}_{2}, \mathrm{NEt}_{2}
$$

$\mathrm{NH}_{3}$ therefore plays a prominent role in the deposition process, by means of either gas-phase or surface reactions or both. To this point, the gas-phase chemistry has been studied in more depth 
than the surface reactions. TDMAT and $\mathrm{NH}_{3}$ undergo a gas-phase transamination reaction, $34-37$ with dimethylamine as the only clearly identified product. On the other hand, $\mathrm{TiCl}_{4}$ and $\mathrm{NH}_{3}$ form complexes with each other $10,30,31,38,39$ at temperatures below $\sim 523 \mathrm{~K} .{ }^{16}$ In the only previous surface study, Truong et al. ${ }^{40}$ speculated that adsorbed $\mathrm{NHx}$ species could react with adsorbed TDMAT at low pressures $\left(<10^{-4}\right.$ torr) to produce low-carbon films. They also briefly examined the reaction of $\mathrm{NH}_{3}$ on TiNx surfaces, but the results were not fully analyzed. In order to further clarify the role of surface processes involving $\mathrm{NH}_{3}$ in TiN CVD, we conducted a more detailed investigation of the adsorption and desorption kinetics of $\mathrm{NH}_{3}$ on $\mathrm{TiN}$, the results of which are summarized in this section.

We also investigated the thermal stability of TiN. Since TiN CVD takes place at elevated temperatures $(450-1000 \mathrm{~K})$, it is important to understand the film's behavior under these conditions. Also, its ability to withstand high temperatures has implications for TiN used in wearand corrosion-resistant coatings. One question that can be addressed by UHV analytical techniques is the temperature-dependent rate of TiN decomposition. Entropy considerations dictate that at high temperatures, TiN should be unstable with respect to dissociation to Ti and $\mathrm{N}_{2}$. The desorption of $\mathrm{N}_{2}$ from the TiN surface is also important since Equation 4 suggests that $\mathrm{N}_{2}$ is a product of the deposition reaction, as required to balance the formal reduction in the oxidation state of the titanium from +4 to +3 ; however, evolution of $\mathrm{N}_{2}$ has not been documented. There are no obvious gas-phase pathways for producing $\mathrm{N}_{2}$, so it has generally been assumed that $\mathrm{N}_{2}$ is produced via a surface reaction. ${ }^{41}$ Thermodynamic calculations ${ }^{42}$ predict $\mathrm{Ti}-\mathrm{N}$ bond strengths for gas-phase compounds in the range of $85-100 \mathrm{kcal} \mathrm{mol}^{-1}$, suggesting that $\mathrm{N}_{2}$ desorption from a TiN surface is too slow to contribute to processes at typical CVD temperatures. In order to verify these calculations, the bond strength of nitrogen to the TiN surface was examined using TPD and Auger electron spectroscopy (AES).

\section{A. Experimental Methods}

The experiments were performed in a vacuum chamber that has been described previously, ${ }^{43,44}$ modified such that the chamber housing the mass spectrometer was pumped by a turbomolecular pump rather than by an ion pump. The TiN samples (Goodfellow Corp.) were sputter-deposited films, 2-3 $\mu \mathrm{m}$ thick, on 8-mm-diameter Ti disks. Tantalum tabs held the sample to a Mo "button" heater at the end of a liquid-N2 cryostat. The temperature was measured by a chromel-alumel thermocouple wedged under one of the tabs. AES showed that $\mathrm{C}$ and $\mathrm{O}$ were the main contaminants, with typical $\mathrm{C} / \mathrm{Ti}$ and $\mathrm{O} / \mathrm{Ti}$ atomic ratios of $<0.2$ and $<0.1$ respectively. Unfortunately, the Ti/N ratio could not be determined by AES since the $\mathrm{N}$ Auger peak at $390 \mathrm{eV}$ overlaps with a Ti peak40 and a standard of known composition was not available. Changes in the AES peak shapes did, however, serve as a diagnostic for depletion of $\mathrm{N}$ from the film following extended sputtering cycles. The depletion was confirmed by a change in the film's color from gold to silver. When this occurred, a new sample was installed.

Before each TPD experiment, the film was sputter-cleaned for 15 minutes and then annealed for 5 minutes. $\mathrm{NH}_{3}$ was admitted through a stainless-steel dosing tube, raising the chamber pressure to roughly $10^{-9}$ to $10^{-8}$ torr. The sample temperature was held at $100 \mathrm{~K}$ during exposure to $\mathrm{NH}_{3}$ and then raised to $850 \mathrm{~K}$ at $5 \mathrm{~K} / \mathrm{s}$ while a TPD spectrum was recorded by the differentiallypumped mass spectrometer. Three different dosing arrangements were used. For some experiments, the sample was turned away from the doser, so that the incident flux could be estimated from the chamber pressure integrated over the exposure time. The sticking probability could then be calculated by comparing the incident flux to the integrated desorption signal during the TPD ramp. Unfortunately, this arrangement led to high background levels of $\mathrm{NH}_{3}$ in the vacuum chamber. To obtain cleaner TPD spectra when measurement of the incident flux was not required, the sample was placed directly in front of the doser during the exposure, minimizing 
adsorption of $\mathrm{NH}_{3}$ on the chamber walls. Under these conditions, however, it was difficult to limit the exposure to obtain low coverage spectra. To further reduce the $\mathrm{NH}_{3}$ background and to provide better control of the magnitude of the exposure, in some cases the $\mathrm{NH}_{3}$ was diluted with Ar in a ratio of $\sim 1: 3$ and the sample was then placed directly in front of the dosing tube.

Additional measurements of the sticking probability were made using the directed-beam doser technique described by Dresser et al. ${ }^{11} \mathrm{NH}_{3}$ was introduced through the doser with the sample facing away from the beam. The chamber pressure was recorded while the sample was rotated into the path of the beam and then later rotated back out. Finally the doser valve was closed. Sharp pressure changes were not achieved, due to adsorption and desorption on the walls of the stainlesssteel doser tubing, but qualitative results could be evaluated.

For studies of thermal decomposition, the same TiN samples were clamped onto a resistivelyheated 0.08-mm-thick Mo support. A W/5\% Re:W/26\% Re thermocouple was spot-welded to the Mo support near the sample. The TiN surface was sputtered briefly but not annealed. AES showed residual oxygen on the surface with typical $\mathrm{O} / \mathrm{Ti}$ atomic ratios of $\sim 0.4$. Since decomposition is a bulk rather than a surface phenomenon, no effort was made to further reduce the surface oxygen with continued sputter cycles. The sample was heated to $1750 \mathrm{~K}$ at a rate of $6.6 \mathrm{~K} / \mathrm{s}$, while monitoring desorption of $\mathrm{N}(\mathrm{m} / \mathrm{e}=14), \mathrm{N}_{2}(\mathrm{~m} / \mathrm{e}=28), \mathrm{Ti}(\mathrm{m} / \mathrm{e}=48)$, and TiN $(\mathrm{m} / \mathrm{e}=62)$ with the mass spectrometer.

The TPD spectra were analyzed by a non-linear least-squares fitting procedure that is an extension of a previous method developed for the analysis of TPD from polycrystalline films. [Allendorf, 1991 \#66] The earlier model assumes that broad first-order desorption spectra are the result of multiple desorption sites with a Gaussian distribution of binding energies. Spectra were fit to find the mean activation energy for desorption, $E_{\mathrm{a}, \mathrm{m}}$, and (, the Gaussian width of the distribution, while holding the pre-exponential factor fixed at $1 \times 10^{13} \mathrm{sec}-1$. In this work, the analysis is extended by including the effect of a finite pumping speed for $\mathrm{NH}_{3}$. Details of this procedure are discussed elsewhere. ${ }^{45}$

\section{B . Results}

Temperature Programmed Desorption. The $\mathrm{NH}_{3}$ TPD spectra exhibit two molecular desorption peaks, as shown in Figure 1. The higher temperature state, at $\sim 350 \mathrm{~K}$, fills first and saturates at a coverage $\left((\theta)\right.$ of $\sim 0.05$ monolayer $(\mathrm{ML})\left(1 \mathrm{ML} \equiv 1 \mathrm{NH}_{3}\right.$ per TiN "molecule", or $\approx 1 \times 10^{15}$ molecules $\mathrm{cm}^{-2}$ ). Then the low temperature state at $140 \mathrm{~K}$ begins to fill and continues to grow without achieving saturation. Although it appears that the intensity of the peak at $350 \mathrm{~K}$ continues to increase, the rise is in fact due to the higher background level from the tail of the lowtemperature peak. Both peaks have a long tail on the high temperature side. Experiments confirm that this signal is not due to a desorption feature, but rather is simply due to continued pumping of $\mathrm{NH}_{3}$ that has desorbed in the lower-temperature peaks. The affect of this tail on the shape of the TPD spectra is accounted for in our analysis.

Non-linear least-squares fitting the TPD spectra using a first-order desorption model yields an activation energy of $7.3 \mathrm{kcal} \mathrm{mol}^{-1}$ for the peak at $140 \mathrm{~K}$. The higher-temperature peak is fit by considering only spectra with coverages less than $0.05 \mathrm{ML}$, where the low-temperature peak has not yet been populated. Figure 2 shows the fits to a series of low-coverage spectra following subtraction of a linear background. An activation barrier of $24 \mathrm{kcal} \mathrm{mol}^{-1}$ in the limit of zero coverage is determined for this peak. 


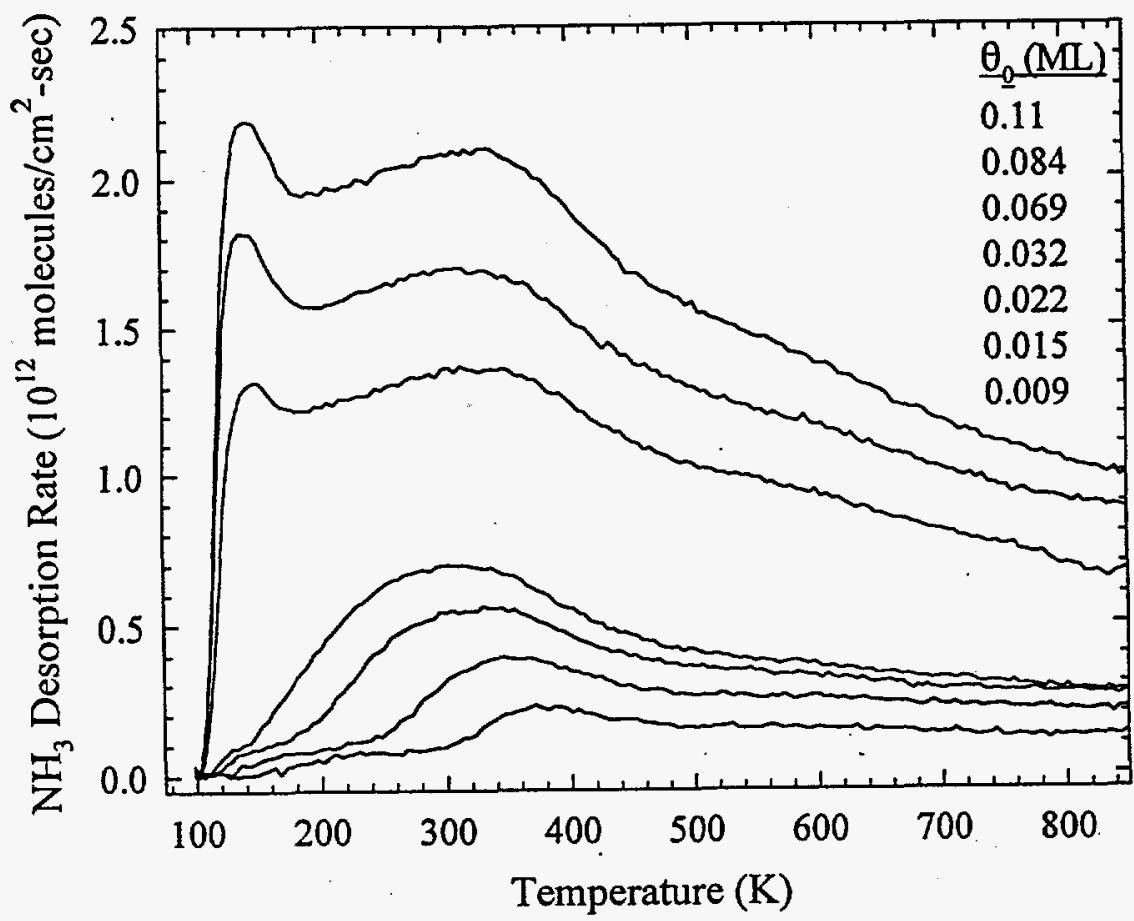

Figure 1. Temperature-programmed desorption spectra of increasing coverages of $\mathrm{NH}_{3}$ from TiN. Curves for $\theta_{0}$ varying from 0.009 to $0.11 \mathrm{ML}$, from bottom to top.

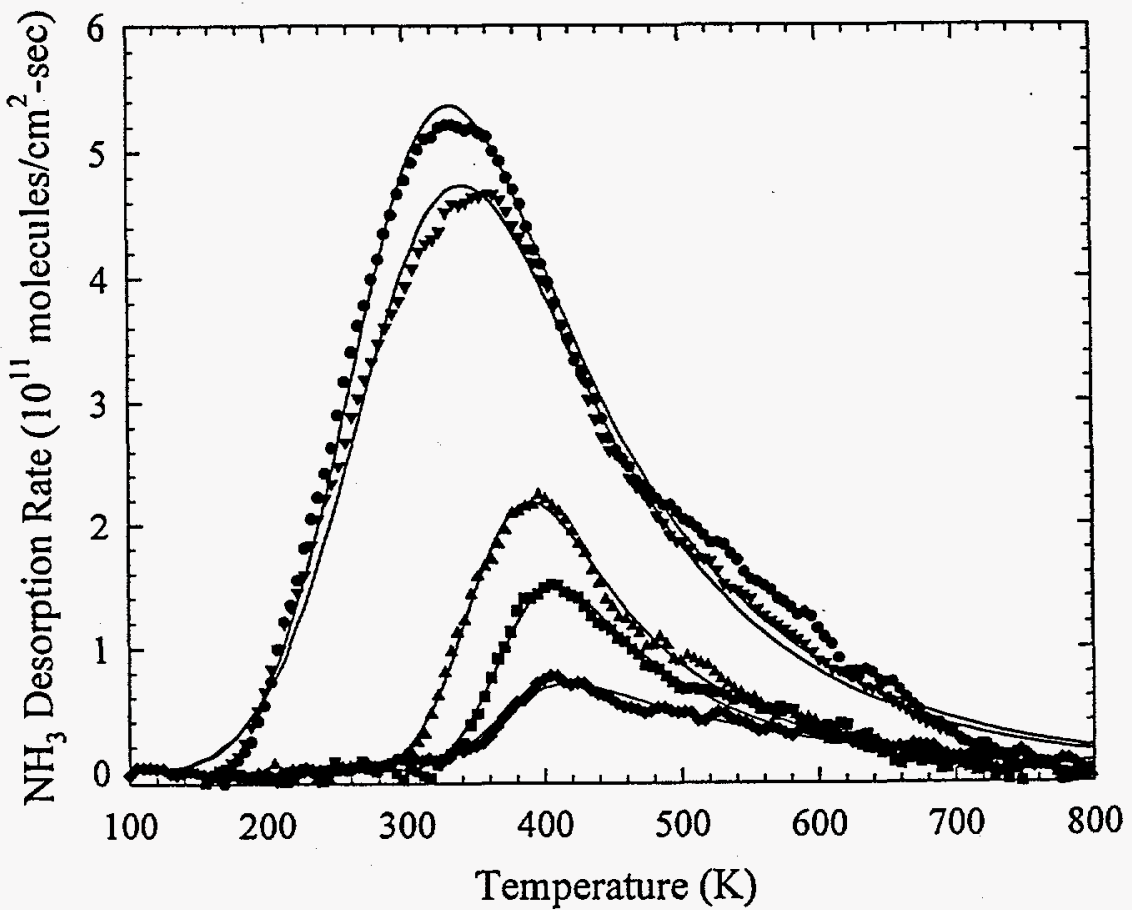

Figure 2. The low-coverage $\mathrm{NH}_{3}$ TPD spectra (symbols) and the fits to the model (solid lines) for different values of the initial coverages $\theta_{0} . \quad\left(\theta_{0}=0.003,0.006,0.024\right.$, and $0.026 \mathrm{ML}$, from bottom to top.) 
The activation energies and saturation coverages determined here can be considered in light of previous TPD studies and the bond energies of various $\mathrm{Ti}$ - and $\mathrm{N}$-containing species to formulate a physical description of the binding states of $\mathrm{NH}_{3}$ on TiN. The low-temperature, high-coverage peak for $\mathrm{NH}_{3}$ desorption from TiN does not saturate, signifying that it is a multilayer of solid $\mathrm{NH}_{3}$. The activation energy for desorption, $7.3 \mathrm{kcal} \mathrm{mol}^{-1}$, is similar to those found for $\mathrm{NH}_{3}$ multilayers on $\operatorname{Pt}(111)^{12}\left(8.6 \mathrm{kcal} \mathrm{mol}^{-1}\right)$ and on $\operatorname{GaAs}(100)^{13}\left(9.8 \mathrm{kcal} \mathrm{mol}^{-1}\right)$. The activation energy associated with the high-temperature peak is in excellent agreement with the estimate of Truong et al. 40

Sticking Probability. Two methods were used to determine the sticking probability of $\mathrm{NH}_{3}$ on TiN. In the first method, the sticking probability at $100 \mathrm{~K}$ into the low-coverage state was calculated by comparing the incident flux to the integrated desorption flux. Only spectra with coverages below $0.05 \mathrm{ML}$, i.e., those exhibiting desorption only from the low-coverage state, were considered. As shown in Figure 3, the surface coverage increases linearly with incident flux, yielding a sticking probability of 0.06 . In the second method, the directed-beam doser technique, the surface temperature was held above the desorption temperature for the high-coverage peak. Measurements at both 150 and $200 \mathrm{~K}$ failed to exhibit the sharp changes in pressure described by Dresser et al. ${ }^{11}$ since the surface was saturated with background $\mathrm{NH}_{3}$ before being moved into the beam path. However, we were able to determine from the beam-doser method that the sticking probability at $100 \mathrm{~K}$ into the low-temperature state is on the order of unity. The rapid saturation of the high-temperature state is consistent with the low value of its maximum coverage.

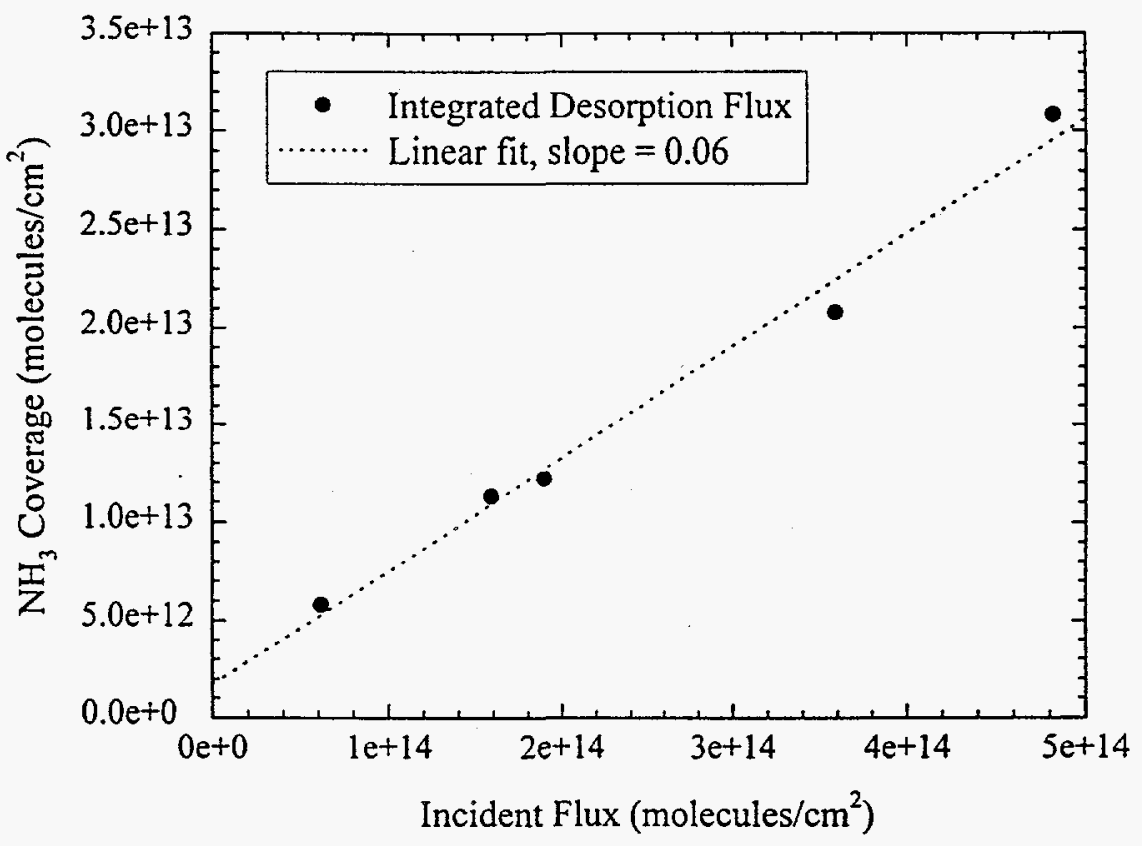

Figure 3. Surface coverage of $\mathrm{NH}_{3}$ vs incident flux. The slope of the line gives the sticking probability.

Decomposition of TiN. Upon heating to $1750 \mathrm{~K}$ in vacuum, TiN decomposes with $\mathrm{N}_{2}$ and $\mathrm{Ti}$ as the only desorption products. Nitrogen is detected by the mass spectrometer at both $\mathrm{m} / \mathrm{e}=28$ and $\mathrm{m} / \mathrm{e}=14$ at temperatures between 1200 and $1600 \mathrm{~K}$. The details of the spectra are not reproducible and most likely depend strongly on the history of the sample and the local morphology of the sputtered film. No desorption is observed at $\mathrm{m} / \mathrm{e}=12$ or $\mathrm{m} / \mathrm{e}=16$ and the ratio of the $\mathrm{m} / \mathrm{e}=14$ signal to that of $\mathrm{m} / \mathrm{e}=28$ matches a reference spectrum of molecular nitrogen, confirming the identification 
of the desorbing species as $\mathrm{N}_{2}$ and not $\mathrm{CO}$. AES also demonstrates the removal of nitrogen from the sample between 1000 and $1750 \mathrm{~K}$, as shown in Figure 4. An Auger spectrum recorded after heating to $1000 \mathrm{~K}$ shows the same ratio of the peak at $390 \mathrm{eV}$ (due to $\mathrm{N}$ and $\mathrm{Ti}$ ) to the peak at 420 $\mathrm{eV}$ (due to Ti) as does a freshly sputtered surface (Fig. 4a). After heating to $1750 \mathrm{~K}$, however (Fig. 4b), the peak at $390 \mathrm{eV}$ decreases due to loss of nitrogen and the $390 \mathrm{eV} / 420 \mathrm{eV}$ ratio is consistent with elemental titanium (Fig. 4c). Finally, the color of the sample changes from gold to silver after heating, confirming the total decomposition of TiN to Ti.

Above $1600 \mathrm{~K}$, atomic $\mathrm{Ti}$ desorbs at a rate that increases exponentially with temperature. The slope of an Arrhenius plot yields a heat of desorption of $107 \mathrm{kcal} \mathrm{mol}^{-1}$, close to the $112.3 \mathrm{kcal}$ mol-1 $^{-1}\left(\Delta H^{\circ}\right.$ vaporization of elemental Ti. ${ }^{14}$ This is further evidence that the surface species remaining after the loss of nitrogen is elemental $\mathrm{Ti}$ and confirms the accuracy of the temperature measurement by the thermocouple.

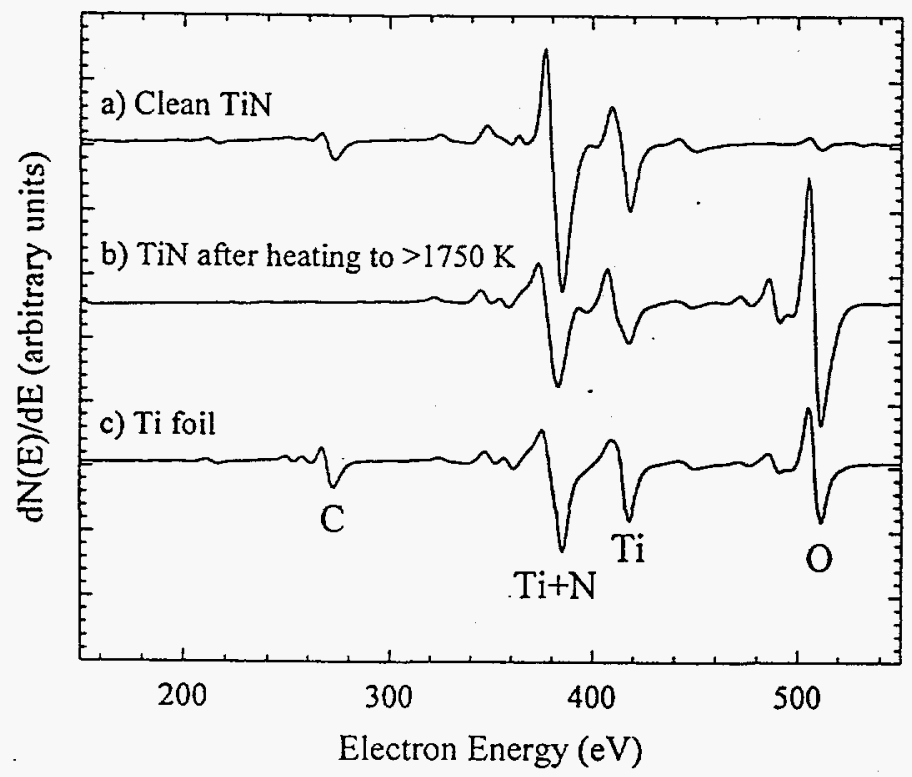

Figure 4. Auger electron spectra of (a) clean TiN, (b) TiN after heating to $>1750 \mathrm{~K}$, and (c) elemental titanium foil.

\section{Discussion}

$\mathrm{NH}_{3}$ adsorption and desorption. Of the two TPD peaks observed, high-temperature $(350 \mathrm{~K})$, lowcoverage peak is the one of most relevance to CVD processes. A qualitative picture of this adsorption state can be obtained by considering the observed sticking coefficient, activation barrier, and coverage dependence. The saturation coverage of $0.05 \mathrm{ML}$ implies that this peak represents desorption from sites that are fairly rare on the surface, perhaps some type of defect in the TiN lattice. 15 Some insight into the nature of this site can be gained by comparing the activation energy of $24 \mathrm{kcal} \mathrm{mol}^{-1}$ with bond strengths for some related gas-phase compounds. The bond dissociation energy of gas-phase $\left(\mathrm{NH}_{2}\right)_{3} \mathrm{Ti}-\mathrm{NH}_{2}$, an analogue of adsorbed, dissociated $\mathrm{NH}_{3}$, is calculated by us using DFT 42 (Sect. II) to be $86.1 \mathrm{kcal} \mathrm{mol}^{-1}$. As described below, dissociation of the TiN lattice has an activation energy of $\sim 80-100 \mathrm{kcal} \mathrm{mol}^{-1}$. The $\mathrm{N}-\mathrm{N}$ bond strength in $\mathrm{H}_{2} \mathrm{~N}-$ $\mathrm{NH}_{2}$ is $65.8 \mathrm{kcal} \mathrm{mol}^{-1}$." All of these are significantly higher than the desorption energy of $\mathrm{NH}_{3}$

\footnotetext{
** It is possible that these minority sites are related to the carbon and/or oxygen impurities on the TiN surface. No correlation was found, however, between the saturation coverage achieved and the carbon Auger signal prior to the
} 
on TiN. Since $\mathrm{NH}_{3}$ apparently does not dissociate on the TiN surface, a more relevant comparison is with $\mathrm{Cl}_{4} \mathrm{Ti}: \mathrm{NH}_{3}$, in which there is a dative bond between $\mathrm{Ti}$ and $\mathrm{N}$. Our calculation (Sect. II) of the bond dissociation energy for this species predicts a value of $17.0 \mathrm{kcal} \mathrm{mol}^{-1}$, 42 which is reasonably close to the $24 \mathrm{kcal} \mathrm{mol}^{-1}$ measured here. Desorption from the molecular chemisorption state of $\mathrm{NH}_{3}$ on $\mathrm{TiO}_{2}(001)$, with $\mathrm{E}_{\mathrm{a}}=19 \mathrm{kcal} \mathrm{mol}^{-1}$, may represent a similar process.

A physical picture for the adsorption of $\mathrm{NH}_{3}$ on TiN can now be constructed, and this is shown in Figure 5. After sputtering and annealing the TiN surface is most likely capped with $\mathbf{N}$ atoms, since $\mathrm{N}$ is much less reactive than $\mathrm{Ti}$. There may be a few locations on the surface, though, that have a different composition. This is represented in Figure 5a by a box around the Ti, as the chemical identity of these sites is not known. When the surface is exposed to small amounts of $\mathrm{NH}_{3}$, it chemisorbs first at these sites, as shown in Figure 5b. The comparisons above suggest that this happens through a dative $\mathrm{N}$ to $\mathrm{Ti}$ bond, and it is desorption from this state that has an activation energy of $24 \mathrm{kcal} \mathrm{mol}^{-1}$. When all of these sites are filled, with a saturation coverage of approximately $0.05 \mathrm{ML}$, adsorption into this state ceases. Additional $\mathrm{NH}_{3}$ incident on the surface, Figure 5c, forms a multilayer. The multilayer, which is held together by hydrogen bonding, desorbs at $\sim 140 \mathrm{~K}$. This picture also explains why there is no separate physisorption peak for the desorption of the first layer of the solid $\mathrm{NH}_{3}$, as there is in some other systems. The $\mathrm{N}-\mathrm{H}$ bonding from the multilayer to the TiN surface is the same as that within the multilayer, so the first layer desorbs at the same temperature as the rest of the multilayer. The two peaks in the $\mathrm{NH}_{3} \mathrm{TPD}$ spectra therefore represent chemisorption and multilayer states.

a)

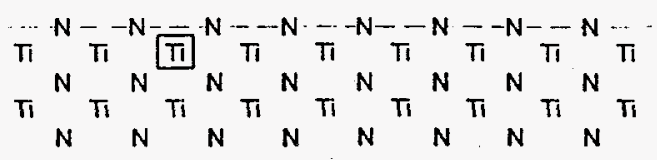

b)

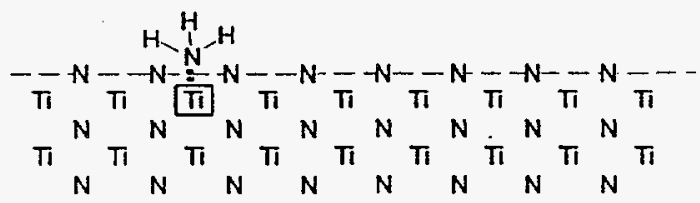

c)

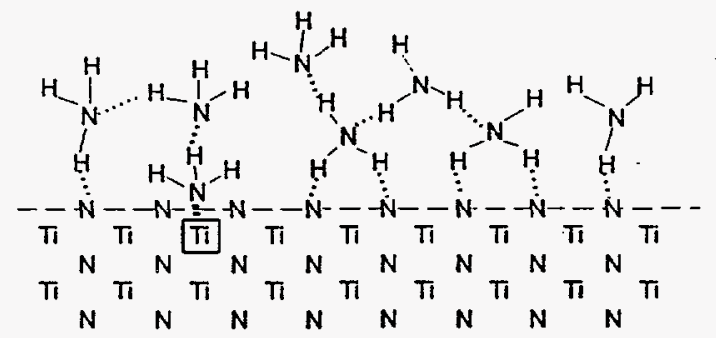

Figure 5. Proposed surface structures for $\mathrm{NH}_{3}$ adsorption on $\mathrm{TiN}$ : (a) annealed TiN surface, (b) low $\mathrm{NH}_{3}$ coverages, (c) high coverages of $\mathrm{NH}_{3}$.

dose. The TiN $\mathrm{T}_{\mathrm{X}}$ substrates used in a previous study ${ }^{40}$ also contained substantial carbon impurities. Further experiments with higher-purity films are required to fully resolve this issue. 
Nitrogen desorption. $\mathrm{N}_{2}$ desorbs from $\mathrm{TiN}$ at much higher temperatures and with more complex spectra than $\mathrm{NH}_{3}$. Because the TPD experiment probes bulk decomposition of TiN and not surface decomposition alone, several elementary processes can contribute to the desorption profiles. These include dissociation of Ti-N bonds in bulk TiN, diffusion of nitrogen to the TiN surface, and desorption of $\mathrm{N}_{2}$ from the surface. It is difficult to positively associate the TPD features with any of these specific rate processes without more detailed measurements and modeling. Since all of these kinetic processes exhibit an Arrhenius form for the temperature dependence, however, a range of $E_{a}$ of $80-100 \mathrm{kcal} \mathrm{mol}^{-1}$ can be obtained using TPD analysis, assuming a prefactor of $10^{13} \mathrm{sec}^{-1}$. These values therefore provide upper and lower limits for the activation energy for decomposition of TiN to $\mathrm{Ti}$ and $\mathrm{N}_{2}$.

These measurements are consistent with the calculated ${ }^{42}$ (Sect. II) (NH2) $3 \mathrm{Ti}^{-\mathrm{NH}_{2}}$ bond strength of $86.1 \mathrm{kcal} \mathrm{mol}^{-1}$, as well as with previous experimental investigations of the thermodynamics of TiN vaporization and decomposition. Hoch et al. ${ }^{46}$ examined the vaporization of TiN in a Knudsen effusion cell and deduced that $\mathrm{TiN}$ decomposes into $\mathrm{Ti}(\mathrm{g})$ and $\mathrm{N}_{2}(\mathrm{~g})$, the same products observed here, but the reaction was detected at a higher temperature $(1987 \mathrm{~K})$ than in the present study. This difference may be attributed to the superior sensitivity of mass spectrometry, used here to detect decomposition products, versus the weight-change method used by Hoch et al. Thus, the decomposition was detected at lower temperatures in this study.

Implications for CVD. The implications of these results for the CVD of TiN can now be considered, keeping in mind that conditions in a deposition reactor differ significantly from the UHV environment of these experiments. Total reactor pressures typically range from $150 \mathrm{mtorr}$ to 760 torr, often with $\mathrm{NH}_{3}$ mole fractions of $\sim 10 \%$, Ti-containing precursor mole fractions of $\sim 1 \%$, and the remainder consisting of carrier gases such as Ar or $\mathrm{N}_{2}$. Substrate temperatures range from $700-1000 \mathrm{~K}$ for $\mathrm{TiCl}_{4} / \mathrm{NH}_{3}$ depositions and $450-850 \mathrm{~K}$ for metalorganic processes.

The activation energy for $\mathrm{NH}_{3}$ desorption from TiN, $24 \mathrm{kcal} \mathrm{mol}^{-1}$, is low enough that $\mathrm{NH}_{3}$ desorbs readily at CVD temperatures. A calculation of steady-state $\mathrm{NH}_{3}$ surface coverage as a function of substrate temperature and incident $\mathrm{NH}_{3}$ flux shows that even under high flux conditions, the surface remains free of $\mathrm{NH}_{3}$ and sites necessary for growth are not prevented from reacting. The $\mathrm{NH}_{3}$ sticking probability determined here, 0.06 , is very close to the saturation coverage in the chemisorption state, $0.05 \mathrm{ML}$. This may mean that the sticking probability is actually limited by the availability of sites, i.e., the incident $\mathrm{NH}_{3}$ molecules that land on "appropriate" sites adsorb with unit probability and the others return to the gas phase. The surface morphology and the concentration of active sites on the sputter-deposited samples used here may differ from those present under CVD conditions. As new layers of $T i$ and $N$ are continually added to the lattice, it is possible that the concentration of active sites may increase and the apparent sticking probability may therefore rise. In addition, there may be other important surface processes, such as surface transamination in the metalorganic case, 40 or surface reactions with $\mathrm{Cl}$ containing species in the inorganic case, that may be important during CVD. The lack of a dissociative adsorption state suggests that adsorption of other species is required for nitrogen incorporation into the films.

The measured molecular sticking probability of 0.06 can also be compared to the results of our model (see Sect. IV below) for the overall reaction mechanism for $\mathrm{TiN}$ deposition from $\mathrm{TiCl}_{4}$ and $\mathrm{NH}_{3}$. Based on a fit to experimentally-measured deposition rates, the-model yields a reactive sticking probability for $\mathrm{NH}_{3}$ of 0.01 . The fact that our measured molecular sticking probability is several times higher than the model sticking probability suggests that adsorption of molecular $\mathrm{NH}_{3}$ is not the rate-limiting step in TiN CVD; we note, however, that the uncertainty in both values is sufficiently high that this distinction is not completely clear. 
The desorption energy for $\mathrm{N}_{2}$ from TiN, experimentally determined to be at least $80 \mathrm{kcal}$ $\mathrm{mol}^{-1}$, is consistent with calculated Ti-to-trivalent- $\mathrm{N}$ bond strengths in gas-phase compounds. $\mathrm{N}_{2}$ is proposed as a product of the TiN CVD reaction, as required to balance the change in oxidation state of the Ti. The desorption energy for $\mathrm{N}_{2}$, though, is too high to for this process to contribute to reactions below $1000 \mathrm{~K}$. This suggests that if $\mathrm{N}_{2}$ is produced during low-temperature CVD of $\mathrm{TiN}$, it occurs by a mechanism that does not involve breaking a Ti to trivalent-N bond.

\section{Reaction Mechanism and Model Predictions}

Several quantitative studies of the TiN deposition rate as a function of process conditions have been reported, and in two of these[Srinivas, 1992 \#67; Buiting, 1991 \#13] a global rate law is inferred from the data. In addition, at least one theoretical description of some of the elementary surface processes has appeared. 48 To date, however, no attempt has been made to derive an overall rate law from a complete reaction mechanism. In this section a schematic but selfconsistent mechanism for this process is described, and an expression for the deposition rate is obtained in terms of the (unknown) individual rate constants. The latter are then evaluated by fitting the predictions of the model to some new experimental data. The results of this analysis are shown to be generally consistent with previous studies.

\section{A. Deposition Model}

In constructing a mechanism for the TiN CVD process, a few general observations must be taken into account. First, the most likely gas-phase reaction appears to be complex formation, 17,49 which will be discussed later. Second, the CVD reaction is essentially irreversible at the temperatures normally used, since $\Delta G$ is strongly negative for $T>600 \mathrm{~K}$. A complicating factor is that the titanium atoms undergo a change in oxidation state from +4 to +3 . As a consequence, the products of the reaction are generally assumed to include gas-phase $\mathrm{N}_{2}$ as well as $\mathrm{HCl}$, and the overall stoichiometry is written as 16,50

$$
6 \mathrm{TiCl}_{4}(\mathrm{~g})+8 \mathrm{NH}_{3}(\mathrm{~g}) \rightarrow 6 \mathrm{TiN}(\mathrm{b})+24 \mathrm{HCl}+\mathrm{N}_{2}(\mathrm{~g})
$$

The notation (b) is used here to indicate a bulk (solid) species, as distinguished from surface species that function only as reaction intermediates.

A surface mechanism that is consistent with the above observations can now be written in terms of the following species:

$$
\begin{aligned}
& \text { Gas: } \quad \mathrm{TiCl}_{4}(\mathrm{~g}) \mathrm{NH}_{3}(\mathrm{~g}) \quad \mathrm{HCl}(\mathrm{g}) \mathrm{N}_{2}(\mathrm{~g}) \\
& \text { Surface: } \mathrm{TiCl}_{3} \text { (s) } \mathrm{TiCl}_{2} \text { (s) } \mathrm{TiCl}(\mathrm{s}) \quad \mathrm{Ti}(\mathrm{s}) \quad \mathrm{Ti}(\mathrm{s}) \quad \mathrm{NH}_{2}(\mathrm{~s}) \quad \mathrm{NH}(\mathrm{s}) \quad \mathrm{N}(\mathrm{s}) \mathrm{N}^{*}(\mathrm{~s}) \mathrm{N}^{* *}(\mathrm{~s}) \\
& \text { Bulk: Ti(b) N(b) }
\end{aligned}
$$

(Adsorbed molecular species such as $\mathrm{TiCl}_{4}$ (s) could also be postulated, but using them leads to an inferior rate law.) A surface species is defined to be one that resides in the topmost layer of the solid, while a bulk species resides in any layer below this. In either case, Ti-N bonds are not explicitly noted. Thus, for example, $\mathrm{TiCl}_{3}(\mathrm{~s})$ is a surface species in which one of the original $\mathrm{Ti}-\mathrm{Cl}$ bonds has been replaced by a $\mathrm{Ti}-\mathrm{N}$ bond, while in $\mathrm{Ti}(\mathrm{s})$ all four of the $\mathrm{Ti}-\mathrm{Cl}$ bonds have been replaced. In $\mathrm{Ti}^{*}(\mathrm{~s})$, however, one of the new $\mathrm{Ti}-\mathrm{N}$ bonds has been severed. The nitrogencontaining species are analogous, so that in $\mathrm{N}^{* *}(\mathrm{~s})$ two of the $\mathrm{N}-\mathrm{Ti}$ bonds have been broken. Keeping in mind the oxidation states in $\mathrm{TiN}$, one sees that $\mathrm{Ti}^{*}(\mathrm{~s})$ is the immediate precursor to a bulk titanium, Ti(b), while $\mathrm{N}(\mathrm{s})$ is the species that becomes $\mathrm{N}(\mathrm{b})$. Also, an $\mathrm{N}_{2}$ molecule is formed 
from two $\mathrm{N}^{* *}(\mathrm{~s})$ species by breaking the last $\mathrm{N}-\mathrm{Ti}$ bond to each. Clearly, whenever a nitrogen surface species loses a bond, a titanium species must do the same.

The likely interactions among the species defined above fall naturally into five groups:

Titanium deposition:

1. $\mathrm{TiCl}_{4}(\mathrm{~g})+\mathrm{NH}_{2}(\mathrm{~s})+\mathrm{Ti}^{*}(\mathrm{~s}) \rightarrow \mathrm{TiCl}_{3}(\mathrm{~s})+\mathrm{NH}(\mathrm{s})+\mathrm{HCl}(\mathrm{g})+\mathrm{Ti}(\mathrm{b})$

2. $\mathrm{TiCl}_{4}(\mathrm{~g})+\mathrm{NH}(\mathrm{s})+\mathrm{Ti}^{*}(\mathrm{~s}) \rightarrow \mathrm{TiCl}_{3}(\mathrm{~s})+\mathrm{N}(\mathrm{s})+\mathrm{HCl}(\mathrm{g})+\mathrm{Ti}(\mathrm{b})$

Nitrogen deposition:

3. $\mathrm{TiCl}_{3}(\mathrm{~s})+\mathrm{NH}_{3}(\mathrm{~g})+\mathrm{N}(\mathrm{s}) \rightarrow \mathrm{TiCl}_{2}(\mathrm{~s})+\mathrm{NH}_{2}(\mathrm{~s})+\mathrm{HCl}(\mathrm{g})+\mathrm{N}(\mathrm{b})$

4. $\mathrm{TiCl}_{2}(\mathrm{~s})+\mathrm{NH}_{3}(\mathrm{~g})+\mathrm{N}(\mathrm{s}) \rightarrow \mathrm{TiCl}(\mathrm{s})+\mathrm{NH}_{2}(\mathrm{~s})+\mathrm{HCl}(\mathrm{g})+\mathrm{N}(\mathrm{b})$

5. $\mathrm{TiCl}(\mathrm{s})+\mathrm{NH}_{3}(\mathrm{~g})+\mathrm{N}(\mathrm{s}) \rightarrow \mathrm{Ti}(\mathrm{s})+\mathrm{NH}_{2}(\mathrm{~s})+\mathrm{HCl}(\mathrm{g})+\mathrm{N}(\mathrm{b})$

Surface condensation:

6. $\mathrm{TiCl}_{3}(\mathrm{~s})+\mathrm{NH}_{2}(\mathrm{~s}) \rightarrow \mathrm{TiCl}_{2}(\mathrm{~s})+\mathrm{NH}(\mathrm{s})+\mathrm{HCl}(\mathrm{g})$

7. $\mathrm{TiCl}_{3}(\mathrm{~s})+\mathrm{NH}(\mathrm{s}) \rightarrow \mathrm{TiCl}_{2}(\mathrm{~s})+\mathrm{N}(\mathrm{s})+\mathrm{HCl}(\mathrm{g})$

8. $\mathrm{TiCl}_{2}(\mathrm{~s})+\mathrm{NH}_{2}(\mathrm{~s}) \rightarrow \mathrm{TiCl}(\mathrm{s})+\mathrm{NH}(\mathrm{s})+\mathrm{HCl}(\mathrm{g})$

9. $\mathrm{TiCl}_{2}(\mathrm{~s})+\mathrm{NH}(\mathrm{s}) \rightarrow \mathrm{TiCl}(\mathrm{s})+\mathrm{N}(\mathrm{s})+\mathrm{HCl}(\mathrm{g})$

10. $\mathrm{TiCl}(\mathrm{s})+\mathrm{NH}_{2}(\mathrm{~s}) \rightarrow \mathrm{Ti}(\mathrm{s})+\mathrm{NH}(\mathrm{s})+\mathrm{HCl}(\mathrm{g})$

11. $\mathrm{TiCl}(\mathrm{s})+\mathrm{NH}(\mathrm{s}) \rightarrow \mathrm{Ti}(\mathrm{s})+\mathrm{N}(\mathrm{s})+\mathrm{HCl}(\mathrm{g})$

Bond breaking:

12. $\mathrm{Ti}(\mathrm{s})+\mathrm{N}(\mathrm{s}) \rightarrow \mathrm{Ti}^{*}(\mathrm{~s})+\mathrm{N}^{*}(\mathrm{~s})$

13. $\mathrm{Ti}(\mathrm{s})+\mathrm{N}^{*}(\mathrm{~s}) \rightarrow \mathrm{Ti}^{*}(\mathrm{~s})+\mathrm{N}^{* *}(\mathrm{~s})$

$\mathrm{N}_{2}$ liberation:

14. $2 \mathrm{Ti}(\mathrm{s})+2 \mathrm{~N}^{* *}(\mathrm{~s})+2 \mathrm{~N}(\mathrm{~b}) \rightarrow 2 \mathrm{Ti}^{*}(\mathrm{~s})+\mathrm{N}_{2}(\mathrm{~g})+2 \mathrm{~N}(\mathrm{~s})$

Note that each step automatically conserves the total number of surface species, or sites. In \#1, for example, when a gas-phase $\mathrm{TiCl}_{4}$ attaches to the surface, a Ti*(s) becomes buried and is thus now a bulk species instead. (With this interpretation, it is clear that \#1-5 are essentially bimolecular processes, despite the appearance of three reactants.) As a result, one bulk-phase atom is added to the solid for each one that arrives from the gas. A reverse process occurs in \#14. As with the others, this step may or may not be truly elementary.

A kinetic law for the deposition process can be derived by assuming that the surface species concentrations are at steady state. Details of this derivation can be found in Ref. 41 . The resulting rate law is:

$$
r=\frac{3 \lambda}{4\left(\phi_{n}+2\right)^{2}}\left\{\left[\frac{\lambda}{2 \delta}+\rho^{2} \frac{\left(\phi_{n}+2\right) \theta \phi_{t} \phi_{n}}{1+\phi_{t}+\theta \phi_{t} \phi_{n}}\right]^{1 / 2}-\left(\frac{\lambda}{2 \delta}\right)^{1 / 2}\right\}^{2}
$$


where $r$ is the TiN deposition rate and $\alpha, \beta, \gamma, \lambda$, and $\delta$ correspond to the rate constants each of the five types of reactions listed above and it is assumed that the rates for all reactions within the group are equal. In addition, $\psi_{t}=(\nu u, \supset \gamma)_{\mathrm{TiCl}}, \psi_{n}=\left(\nu \mu / 4 \gamma \mu_{\mathrm{NH}}\right.$, and $\theta=\gamma / 5 \lambda$. This is obviously rather complicated, but the behavior in various limiting cases is simple and physically realistic. For example, if $\phi_{t}$ and $\phi_{n}$ are both arbitrarily small, then

$$
r \approx \frac{25}{384} \delta\left(\frac{\alpha \beta \rho^{2}}{\gamma \lambda} \cdot C_{\mathrm{TiCl}_{4}} \cdot C_{\mathrm{NH}_{3}}\right)^{2}
$$

and the overall reaction is second-order in each reactant. On the other hand, if $\phi_{n}$ is arbitrarily small but $\phi_{t} \gg 1$, then

$$
r \approx \frac{3}{128} \delta\left(\frac{\beta \rho^{2}}{\lambda} \cdot C_{\mathrm{NH}_{3}}\right)^{2}
$$

so that the reaction is still second-order in $\mathrm{NH}_{3}$ but now zeroth-order in $\mathrm{TiCl}_{4}$. This accords reasonably well with the results that have been reported in the literature; [Srinivas, $1992 \# 67$; Buiting, 1991 \#13] a small negative order in $\mathrm{TiCl}_{4}$ is actually observed, but this has been attributed to competing gas-phase complex formation.

\section{B . Evaluation of Rate Constants}

Since there are currently no methods available for calculating $\alpha, \beta, \gamma, \lambda$, and $\delta$ from first principles, the only option is to infer them from experimental data for the overall deposition rate. In order to account for such effects as mass transport and reactant depletion, one must use the mechanism in conjunction with a computational reactor model. Unfortunately, literature studies generally fail to specify some key parameters, such as the surface/volume ratio and the residence time, that would be necessary input to a reactor simulation. At the time this model was developed, the only data set for which complete was available is that generated recently at Sandia/New Mexico in an MRC rotating disk reactor. ${ }^{51}$ Therefore, we used this data to determine the rate constants in the analysis that follows.

As noted above, the expression in Eq. (6) is at minimum of order 0 in $\mathrm{TiCl}_{4}$, whereas most experimental studies show a small negative order. This has been attributed to a competing gasphase reaction that produces the (possibly) nonreactive complex $\mathrm{I}^{\prime} \mathrm{iCl}_{4} \cdot 2 \mathrm{NH}_{3} \cdot{ }^{16}$ Therefore, the surface mechanism will be augmented here with the homogeneous reaction

$$
\mathrm{TiCl}_{4}+2 \mathrm{NH}_{3} \rightarrow \mathrm{TiCl}_{4} \cdot 2 \mathrm{NH}_{3}
$$

having a third-order rate constant $k$. The supposition is that an increasing inlet concentration of $\mathrm{TiCl}_{4}$ causes additional $\mathrm{NH}_{3}$ to be tied up in complexes and thus decreases the deposition rate, which is generally observed to have a strong positive order in $\mathrm{NH}_{3}$.

In the Sandia study, 51 the deposition rate was measured as a function of the inlet concentration of $\mathrm{TiCl}_{4}$, but not $\mathrm{NH}_{3}$. Furthermore, experiments were carried out at only one substrate temperature $(903 \mathrm{~K})$, so all computed surface rate constants will refer to this temperature. However, there was a substantial temperature gradient between the substrate and the inlet showerhead (at $623 \mathrm{~K}$ ), so an activation energy $E$ will be used in conjunction with the gas-phase rate constant $k$. There are thus 7 adjustable parameters to be determined by optimizing the fit to the experimental deposition rates over the entire range of $\mathrm{TiCl}_{4}$ concentrations. For any given set 
of parameters, the predicted deposition rates are computed from Sandia's SPIN 52 code. The pressure is in all cases fixed at 20 Torr, the inlet $\mathrm{NH}_{3}$ mole fraction varies slightly from 0.0196 to 0.0192 , and the value of $\rho$, as computed from the bulk density of TiN, is $3.61 \times 10^{-4} \mathrm{~mol} \mathrm{~cm}^{-2}$.

A near-optimum fit to the rotating disk reactor data is shown in Figure 6; the root-mean-square relative deviation between the experimental and theoretical values is $8.27 \%$. On the initial, rising portion of the curve, the $\mathrm{TiCl}_{4}$ concentration at the substrate is reduced so severely that the intrinsic deposition rate is no longer in the zero-order regime, and the deposition is limited by the supply of this reactant. On the remainder of the curve, depletion of $\mathrm{TiCl}_{4}$ is no longer an issue, and the deposition rate falls slowly due to the effect of the gas-phase complexing reaction.

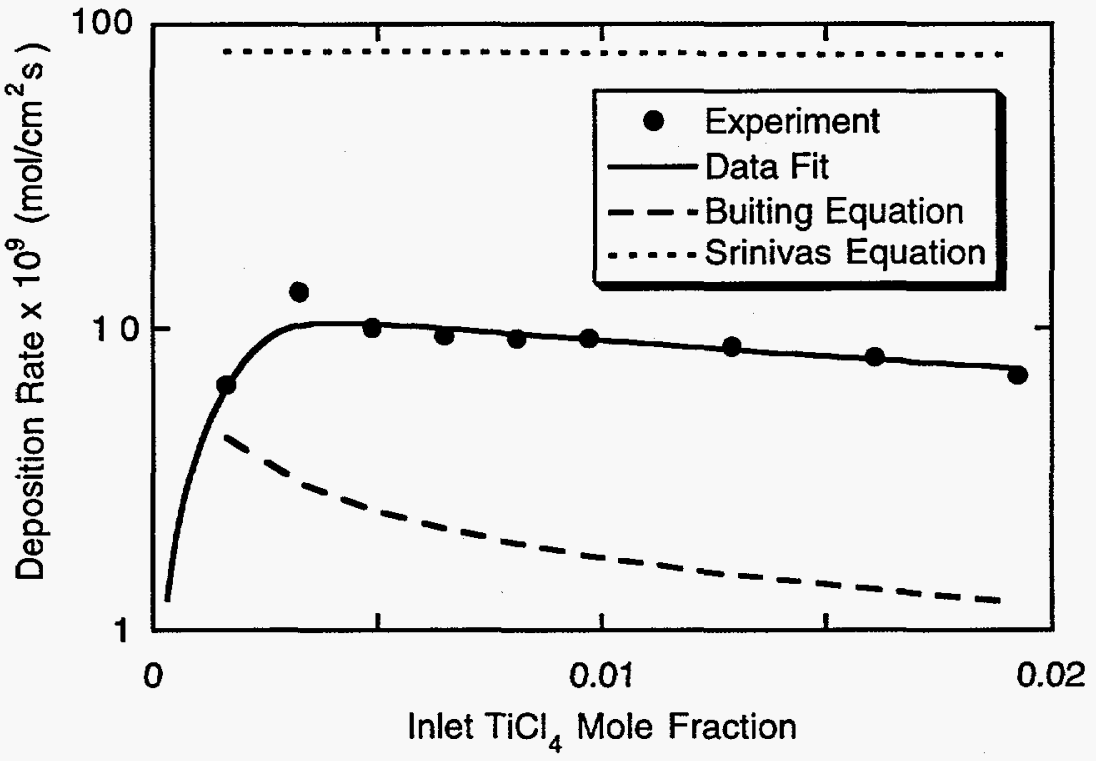

Figure 6. Optimized fit of deposition data from Sandia/MRC rotating disk reactor.

Since the experimental data set spans a limited range of process conditions, the fitting procedure does not provide firm values for all of the unknown rate parameters. The curve in Figure 6 was obtained using $E=76.0 \mathrm{kcal} \mathrm{mol}^{-1}$ and the following values in $\mathrm{cm}-\mathrm{mol}-\mathrm{s}$ units: $k=1.75 \times 10^{18}, \quad \alpha=1.22 \times 10^{21}, \quad \beta=1.90 \times 10^{17}, \quad \gamma=3.09 \times 10^{10}, \quad \lambda=8.37 \times 10^{10}$, and $\delta=7.00 \times 10^{2 \prime}$. The results for $\alpha$ and $\beta$ correspond to reactive sticking coefficients of 1.00 (the maximum permissible) and 0.0093 for $\mathrm{TiCl}_{4}$ and $\mathrm{NH}_{3}$, respectively. (A substantially improved fit can be achieved if the value of $\alpha$ is not constrained in this way.) The value of $E$ is unrealistically large and has the effect of confining the complexing reaction to the immediate vicinity of the substrate. This suggests that the negative reaction order in $\mathrm{TiCl}_{4}$ may be due to a more complicated gas-phase process or even a heterogeneous reaction.

As noted earlier, lack of information about some reactor parameters makes it difficult to analyze rigorously the experimental data available in the literature. However, if one assumes that the experiments were carried out under differential conditions, i.e., in the absence of significant reactant depletion, then the analysis is feasible. The data in References 17 and 47 are a natural choice to use, since they refer to temperatures close to that used in the Sandia study (although the pressures are lower by two orders of magnitude); furthermore, the experiments of Srinivas[Srinivas, 1992 \#67] were designed to minimize reactant depletion. Rather than re- 
optimizing the rate constants, however, we elect to use those already computed and simply predict the deposition rates for the new data sets. To provide a fair comparison, the experimental values are first adjusted to $903 \mathrm{~K}$ by using the activation energies quoted in the respective articles.

The results of this procedure are shown in Figures $7-9$. Clearly, the model tends to underpredict the observed deposition rates, although the discrepancy is at most a factor of 2.7 for the near-differential experiments of Srinivas.[Srinivas, 1992 \#67] Since this approach necessarily ignores the depletion effect of the complexing reaction, the observed negative reaction orders in $\mathrm{TiCl}_{4}$ cannot be reproduced; the predicted order is slightly positive. As expected, this is a more serious problem for the non-differential conditions of Buiting. ${ }^{17}$ On the other hand, the observed trends in the deposition rate with $\mathrm{NH}_{3}$ concentration are predicted quite well.

By contrast, if the purely empirical equations given by Buiting and Srinivas are compared to the Sandia data, then the agreement is poor even where reactant depletion is modest; see Figure 6. It thus appears that the new expression is valid over a wider range of pressures.

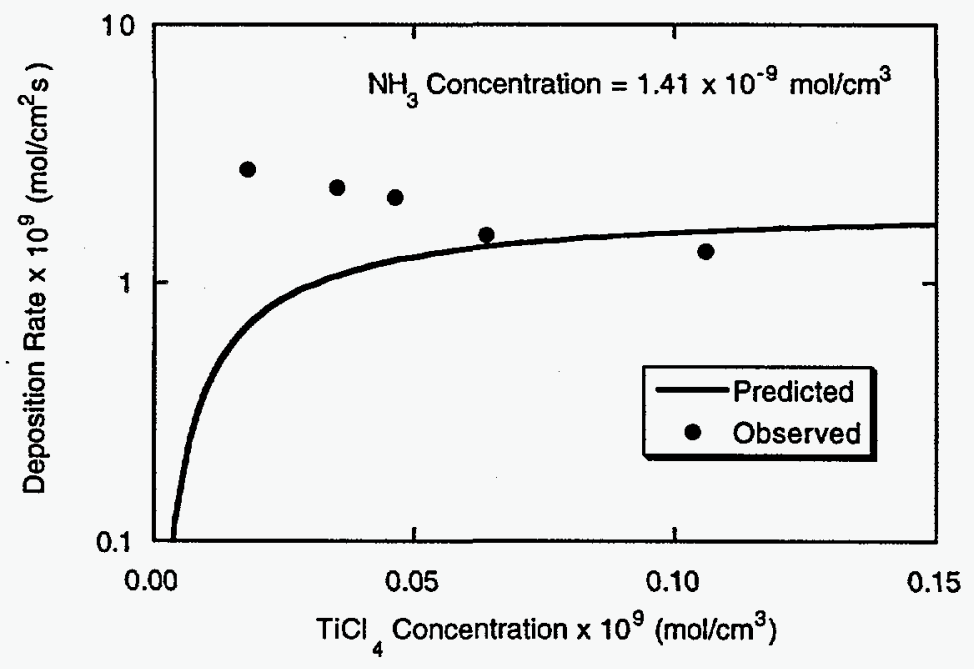

Figure 7. Predicted $\mathrm{TiCl}_{4}$ dependence of the TiN deposition rate vs. observed deposition rates (adjusted to $903 \mathrm{~K}$ ) reported by Buiting et al.

\section{Stagnation-Flow Reactor for TiN CVD}

Although there are many reports of TiN deposition rates in the literature, most of these investigations used reactor configurations that are very difficult to model. In some cases, two- or three-dimensional flow patterns are present, making computer simulations extremely time consuming, particularly when complex chemical reaction mechanisms, such as the one discussed in Sect. IV, are involved. In addition, some reports lack key data, such as flow rates and reactor dimensions, needed to perform computer simulations. As a result, it was necessary as part of this project to obtain deposition rates under controlled laboratory conditions, using a reactor geometry that is practical to simulate using numerical methods. 


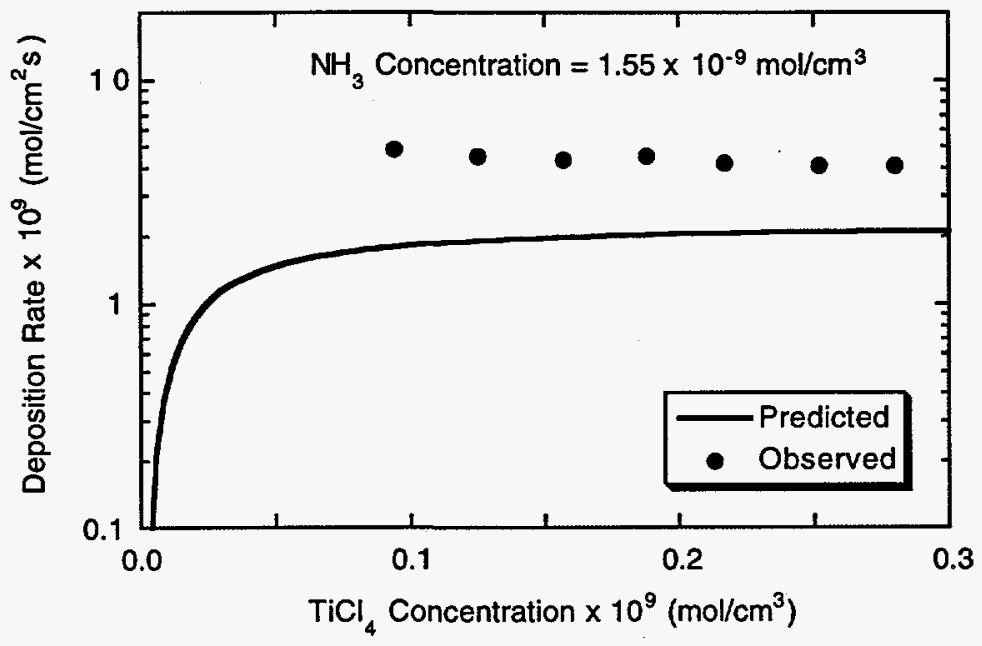

Figure 8. Predicted $\mathrm{TiCl}_{4}$ dependence of the TiN deposition rate vs. observed deposition rates (adjusted to $903 \mathrm{~K}$ ) reported by Srinivas et al.

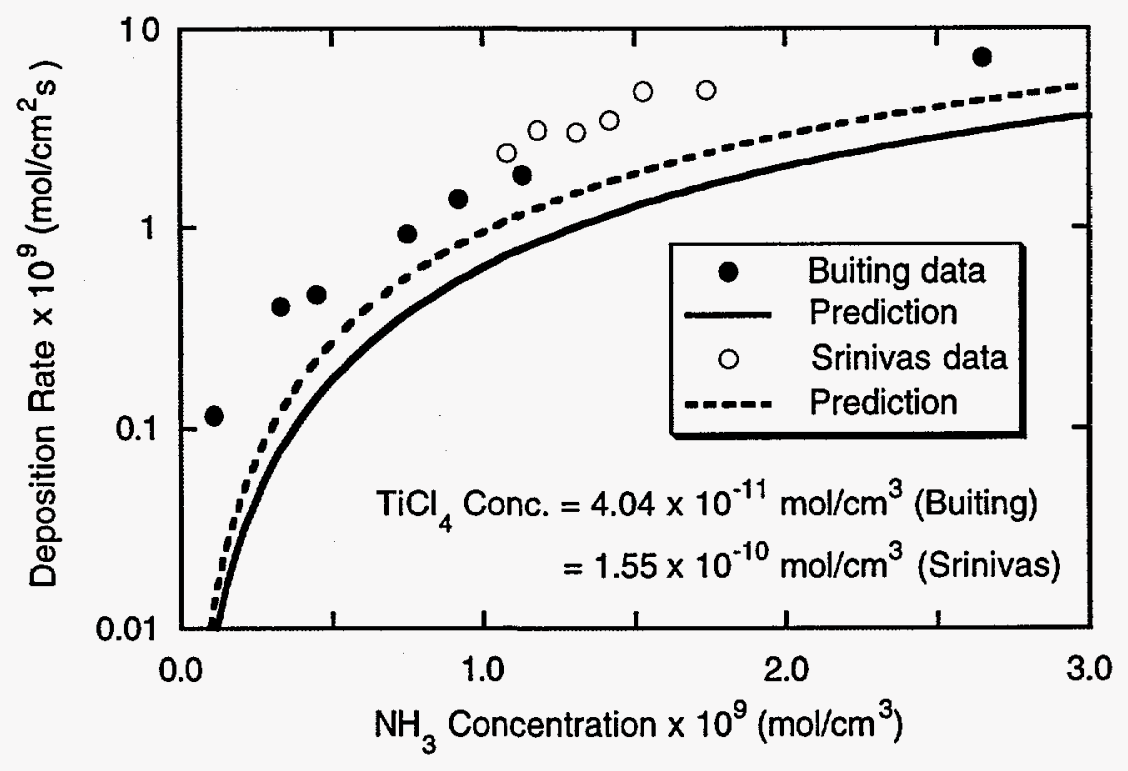

Figure 9. Predicted $\mathrm{NH}_{3}$ dependence of the TiN deposition rate vs. deposition rates (adjusted to $903 \mathrm{~K}$ ) reported by Buiting et al. and Srinivas et al.

In this section, we describe a new reactor designed and constructed at Sandia for the purpose of measuring TiN deposition rates. It employs a stagnation-flow geometry, for which the equations describing the nominally two-dimensional flow can be solved by a separation-ofvariables transformation, thereby reducing them to a system of ordinary differential equations. [von Karman, 1921 \#8] Although this transformation is, in principal, valid only for an infiniteradius disk, in practice it can provide an excellent approximation to the flow over a finite-radius disk if the reactor operating parameters are chosen properly. In particular, convective forces must 
be much stronger than buoyant forces, so that two-dimensional recirculation patterns are eliminated from the flow. For this reason, the direction of gas flow in the new reactor is upward, which eliminates opposed-flow effects caused by cold gases flowing downward over a heated surface.

The reactor and its component systems, which include a direct liquid injection system for delivery of liquid precursors, a residual gas analyzer for monitoring gas-phase concentrations, and an FTIR spectrometer for on-line monitoring of surface species, are described here. We also discuss an analytical method for predicting the fluid mechanics that provides guidance to the experimenter in the choice of appropriate reactor operating conditions. Measurements of TiN deposition rates for a range of $\mathrm{TiCl}_{4} / \mathrm{NH}_{3}$ mixtures are described in Sect. VI.

\section{A. Reactor Description}

Figure 10 is a schematic of the exterior configuration of the reactor. The reactor chamber consists of a $150-\mathrm{cm}$ stainless-steel cube with $100-\mathrm{cm}-\mathrm{ID}$ openings on all sides and knife-edge vacuum flanges. Windows can be mounted on three sides to allow optical measurements to be made and special fixtures are available for mounting IR-transparent ZnSe windows for use with the FTIR. Reactants and carrier gas enter through heated stainless-steel lines; the direction of flow is upward for reasons discussed above. Flow rates are controlled by mass-flow controllers. The reactor can be evacuated to a base pressure $<10^{-5}$ torr using a turbomolecular pump. During deposition experiments, gases are pumped through the reactor by a $1000 \mathrm{l} / \mathrm{min}$ rotary vane pump; with a total flow rate of $5 \mathrm{slpm}$, the minimum pressure attainable in the reactor is 7.5 torr. Typically, the pressure is controlled by a throttle valve connected to a Baratron pressure sensor.

Figure 11 shows a cross-section of the reactor. The gas inlet system is designed to prevent precursors that react with each other in the gas phase from doing so for as long as possible. Thus, $\mathrm{TiCl}_{4}$ and $\mathrm{NH}_{3}$ are delivered to the 5.0-cm-diameter injector head, which serves as a mixing chamber, through separate lines. Lines used to transport vapor (such as $\mathrm{TiCl}_{4}$ ) from a direct liquid-injection source (DLI; MKS Instruments Inc.), are heated to approximately $353 \mathrm{~K}$ to prevent condensation. Additional reactants, such as $\mathrm{NH}_{3}$, and carrier gas are transported to the injector head through an annular line that surrounds the central injection line from the DLI system. All gases mix in the injector head and then flow through a wire-mesh screen (100 mesh), which acts as a showerhead, creating a uniform velocity profile at the entrance. The injector head is also heated to a temperature $\geq 523 \mathrm{~K}$ to prevent formation of particulates. ${ }^{16}$ An auxiliary gas inlet is provided that allows the one reactant to be injected into the flow downstream of the showerhead. This may be important for reactant combinations for which gas-phase reactions leading to powder formation is very fast (e.g., TDMAT/NH 3 ), which could cause the screen to become clogged. The point of injection relative to the substrate is adjustable from $0-50 \mathrm{~cm}$ by a flexible bellows attached to a micrometer.

The substrate has a diameter of $5.0 \mathrm{~cm}$ and is mounted on a boron-nitride ceramic heater (Advanced Ceramics Corp., Cleveland, $\mathrm{OH}$ ), which is inset on a Macor or stainless-steel platform. Since titanium nitride is an excellent electrical conductor, it is essential that all electrical connections be located far away from the point of deposition. Thus, the electrical leads from the heater are enclosed within 7.5-cm-long boron-carbide tubes, so that the exposed contacts are located in a region where conducting material does not deposit.

Downstream of the substrate, a crimped-capillary controlled leak is mounted that allows a small portion of the gases to be extracted for analysis by a residual gas analyzer (Leibold Inficon). 


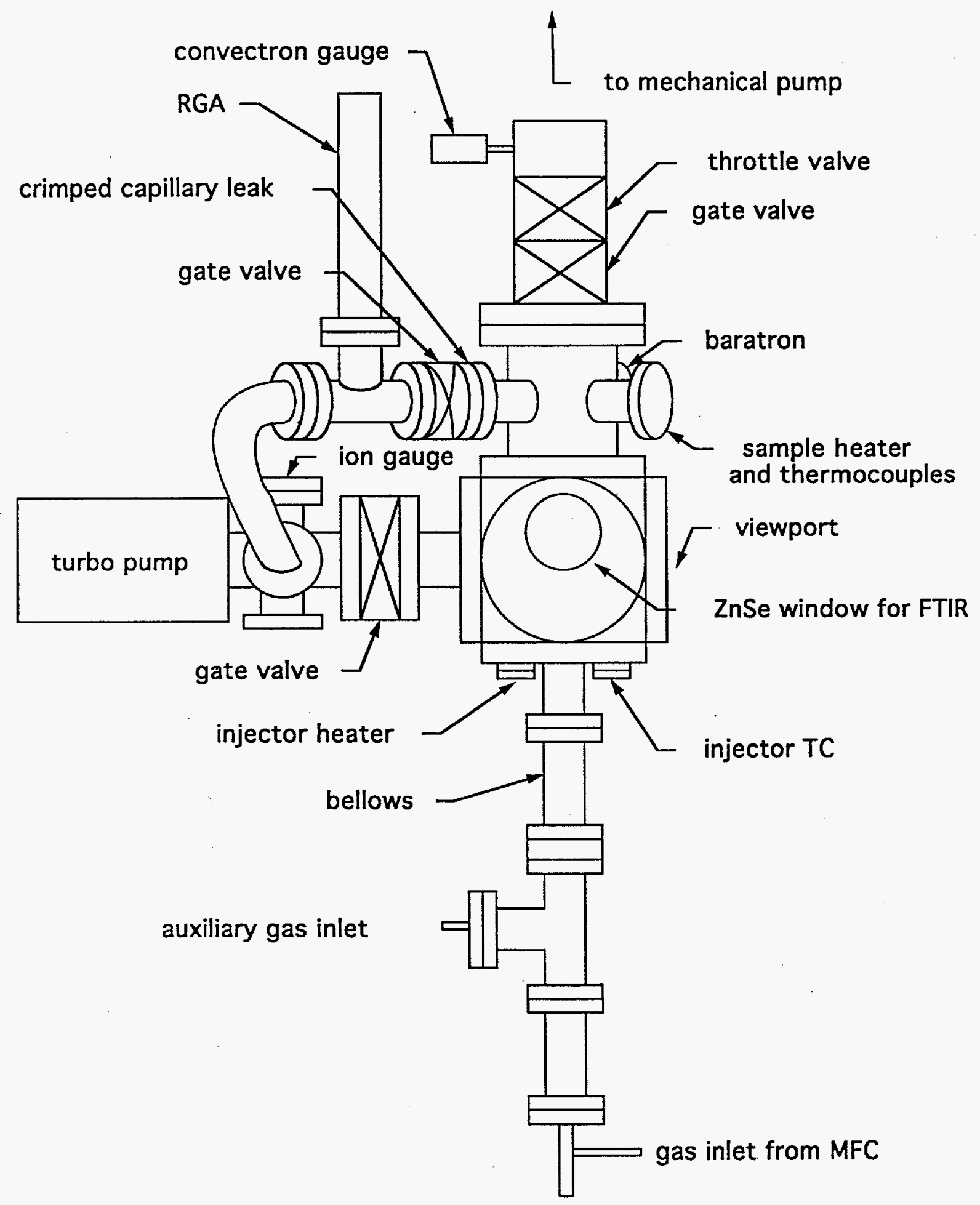

gas inlet from DLI

Figure 10. Schematic of the stagnation-flow reactor. 


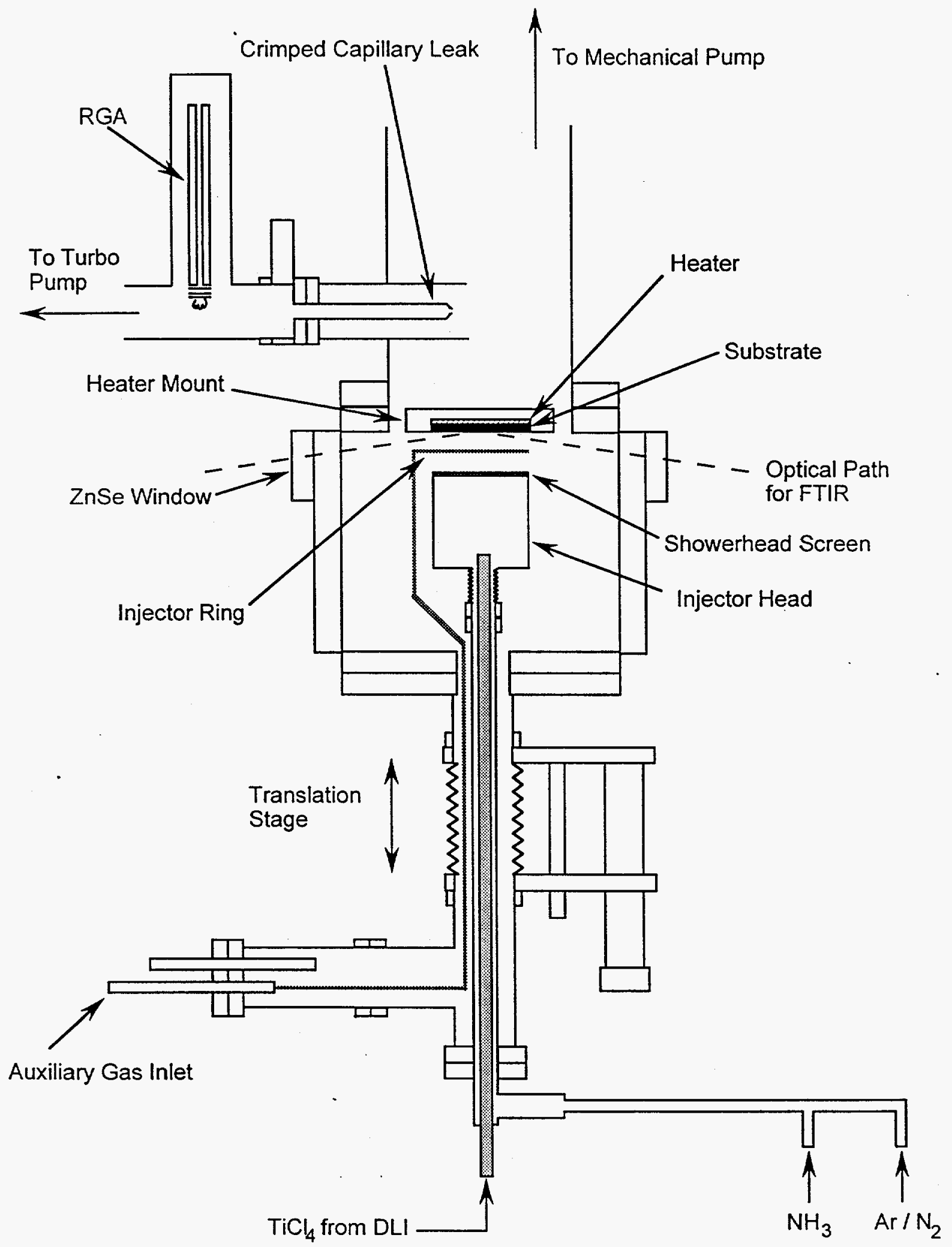

Figure 11. Cross-sectional view of the stagnation-flow reactor. 


\section{B . Reactor Characterization}

The similarity transformation that allows stagnation flow to be treated as a one-dimensional problem assumes that the plate over which the gases flow is infinite in diameter, i.e., there are no wall effects. In an actual reactor, of course, this is not the case; the walls of the reactor confine the flow, causing recirculation patterns to develop that may affect uniformity of the deposit thickness. In addition, the thickness of the temperature and mass-flow boundary layers may exceed the distance between the showerhead and the substrate, causing reaction or even deposition to occur on the showerhead. Although these are all undesirable, identifying the conditions under which they occur can be difficult to determine experimentally. Alternatively, two-dimensional computer models can be used to guide the experimenter in determining appropriate reactor operating conditions.

In this investigation, we used the computer code CURRENT 54 to simulate the fluidmechanical environment in the reactor under the conditions used to deposit titanium nitride films. CURRENT is designed for applications involving two-dimensional, transient or steady-state, low Mach-number flow and heat transfer, and is linked to the CHEMKIN software libraries that allow multi-component transport, gas-phase chemistry, and surface chemistry to be included in the simulation.

Calculations were performed for a range of total flow rates and reactor pressures and several assumptions are made in all cases. First, we assume that the power supplied to the substrate by the heater is uniform, resulting in a constant temperature across the substrate. Second, since the diameter of the heater is smaller than the platform on which it is mounted, the outer edges of the platform are not as effectively heated as the substrate, resulting in a lower temperature at the edges. No quantitative measurement of the edge temperature was made, so in the calculations we assume that the temperature decreases linearly from the substrate edge to $573 \mathrm{~K}$ at the outermost edge. Third, since the reactants $\mathrm{TiCl}_{4}$ and $\mathrm{NH}_{3}$ typically constitute less than 1 vol. \% of the total flow, we assume that an accurate simulation of the reactor can be obtained using pure carrier gas (nitrogen in this case). Finally, we assume that the velocity profile at the inlet is constant, which is not unreasonable because of the screens employed. Calculations were performed for an inletsubstrate separation of $2.54 \mathrm{~cm}$.

The CURRENT calculations suggest that the operating conditions employed for deposition (see Sect. VI) should produce one-dimensional flow that can be simulated using the SPIN 52 code for stagnation- and rotating-disk reactor geometries. Typical results are illustrated by Fig. 12, which shows the stream function and temperature fields for three different nitrogen flow rates when the reactor is operating at 6.0 torr with a substrate temperature of $873 \mathrm{~K}$. An inlet gas temperature of $523 \mathrm{~K}$ was used, based on the reading of a thermocouple attached to the mixing chamber. The plots show that the thickness of the thermal boundary layer (defined as $0.95^{*}\left(T_{\max }\right.$ - $\left.T_{\text {inlet }}\right)$ ) decreases as the flow rate increases. At $200 \mathrm{sccm}$ (Fig. 12A), the boundary layer nearly fills the region between the inlet and the substrate, as shown by the thickness of the region between the $523 \mathrm{~K}$ and $873 \mathrm{~K}$ isotherms (essentially the region between the dark blue and bright red zones in the figure). As the flow increases, however, this thickness decreases; at 2,000 sccm (Fig. $12 \mathrm{~B}$ ), the thermal boundary layer is significantly smaller than the inlet-substrate gap. In all three cases, mass transport to the substrate appears to be uniform; there are no recirculation zones interacting directly with the substrate (although such zones do exist in the dead volume between the mixing chamber and the reactor walls; see Figs. 12B and C). We conclude from these results that uniform deposition rates should be achievable across the substrate over the range of flow rates examined. In addition, deposition on the showerhead should not be a problem, as long as the total flow rate is maintained at $\geq 200 \mathrm{sccm}$.

The results of the CURRENT calculations can be compared with predictions of a simple nondimensional analysis that predicts the thickness of the thermal boundary layer. ${ }^{55}$ The thermal 
boundary-layer thickness $Z_{\mathrm{bl}}$ can be defined as the distance at which the gas temperature $T=$ $0.95 *\left(T_{\max }-T_{\text {inlet }}\right)$. The non-dimensional analysis then predicts that $Z_{\mathrm{bl}}=2.4 * r_{\mathrm{sub}} /\left(\operatorname{Re}(\mathrm{sub})^{0.5}\right)$, where $r_{\text {sub }}$ is the radius of the substrate and $\operatorname{Re}(\mathrm{sub})$ is the substrate Reynolds number (defined as $u \rho r_{\text {sub }} / \mu$, where $u$ is the average gas velocity, $\rho$ is the gas density, and $\mu$ is the viscosity). Figure 13 shows the centerline temperature as a function of distance from the substrate, from which $Z_{\mathrm{bl}}$

can be determined. Results of the non-dimensional analysis are compared with the values of $Z_{\mathrm{bl}}$ determined from the CURRENT calculations in Table IV. Although the good agreement of the absolute numbers is probably fortuitous (the value of 2.4 assigned to the scaling factor is somewhat arbitrary), the similar trends exhibited by the two methods indicate that the nondimensional analysis can be used as a convenient guide to the experimenter. $Z_{b l}$ is plotted in Fig. 14 as a function of nitrogen flow rate (which approximates the total gas flow rate). Since $Z_{\mathrm{bl}}$ should ideally be less than the inlet-substrate distance $(2.54 \mathrm{~cm}$ in our experiments), the minimum usable flow rate is predicted to be roughly $650 \mathrm{sccm}$, as indicated by the dashed lines in the figure.

\section{Deposition Experiments and Comparison With Model Predictions}

The limited amount of useful data in the literature indicates that additional experiments are required to fully validate the model proposed in Sect. IV. The stagnation-flow reactor described in Sect. V provides a suitable environment for measuring deposition rates for comparison with model predictions. In this section we describe the results of experiments in which TiN films were grown on $\mathrm{Si}(100)$ substrates using the precursors $\mathrm{TiCl}_{4}$ and $\mathrm{NH}_{3}$. In addition to measurements of deposition rates, the composition, microstructure, and resistivity of the films were determined. The results establish that good-quality TiN films can be deposited in this reactor and that the gasflow over the substrate approximates one-dimensional (stagnation) flow, leading to fairly uniform film thickness across the substrate. In addition, the results are in good agreement with the proposed model.

\section{A. Experimental Methods}

TiN films were deposited on two-inch-diameter silicon wafers (p-type) with a resistivity of 30-50 $\Omega$-cm purchased from International Wafer Service. The carrier gas used to deliver the reactants to the surface was Nitrogen $(99.999 \%)$ and the reactant gases were $\mathrm{NH}_{3}(99.99 \%$; Matheson) and $\mathrm{TiCl}_{4}$ (99.999\%; Alfa Aesar).

Gas flow rates were determined by mass flow controllers (MKS). TiCl4, a liquid at standard temperature and pressure, was delivered to the reactor using an MKS DLI 25B direct liquid injection system. The total gas flow rate in each experiment was $2065 \mathrm{sccm}$, in which the $\mathrm{NH}_{3}$ flow rate ranged from 20 to $100 \mathrm{sccm}$, the $\mathrm{TiCl}_{4}$ flow rate ranged from 2 to $20 \mathrm{sccm}$, with nitrogen making up the difference. The pressure in the reaction chamber was maintained at 6 torr by an MKS pressure-controller system.

Ammonia was diluted with nitrogen prior to mixing with $\mathrm{TiCl}_{4}$. The two gases were preheated to approximately $100{ }^{\circ} \mathrm{C}$ prior to entering the mixing chamber (Fig. 11). The mixing chamber was kept at a temperature of at least $250^{\circ} \mathrm{C}$ to prevent to formation of a solid titaniumammonia complex. 16

The inlet-substrate distance was adjusted to be $2.54 \mathrm{~cm}$. The temperature at the surface of the substrate was maintained at $600{ }^{\circ} \mathrm{C}$ by mounting the substrate on the boron nitride heater and monitoring the temperature with two thermocouples placed at the edges of the substrate. During deposition the temperature of the walls near the substrate exceeded $120^{\circ} \mathrm{C}$, due to convective and radiative heat transfer from the heated substrate. 


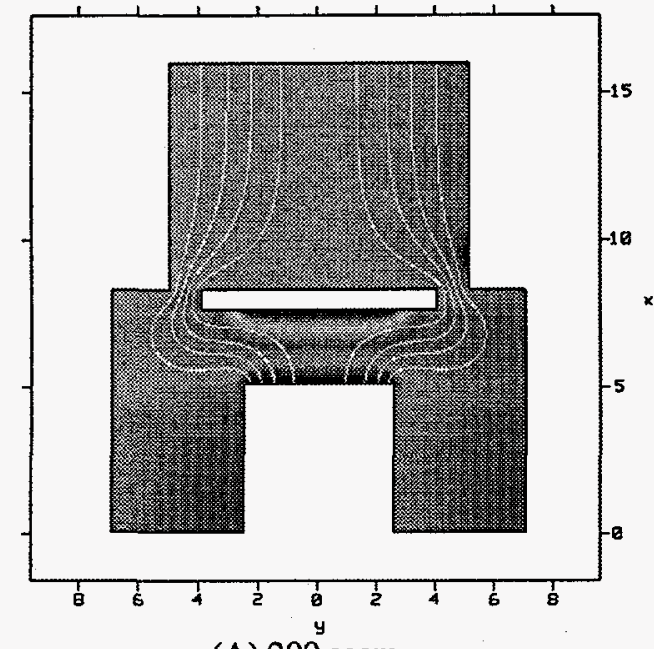

(A) $200 \mathrm{sccm}$

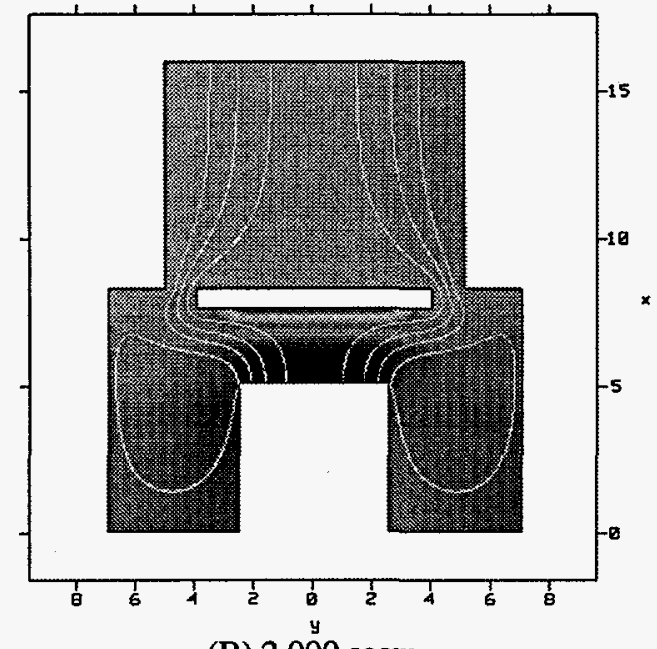

(B) $2,000 \mathrm{sccm}$
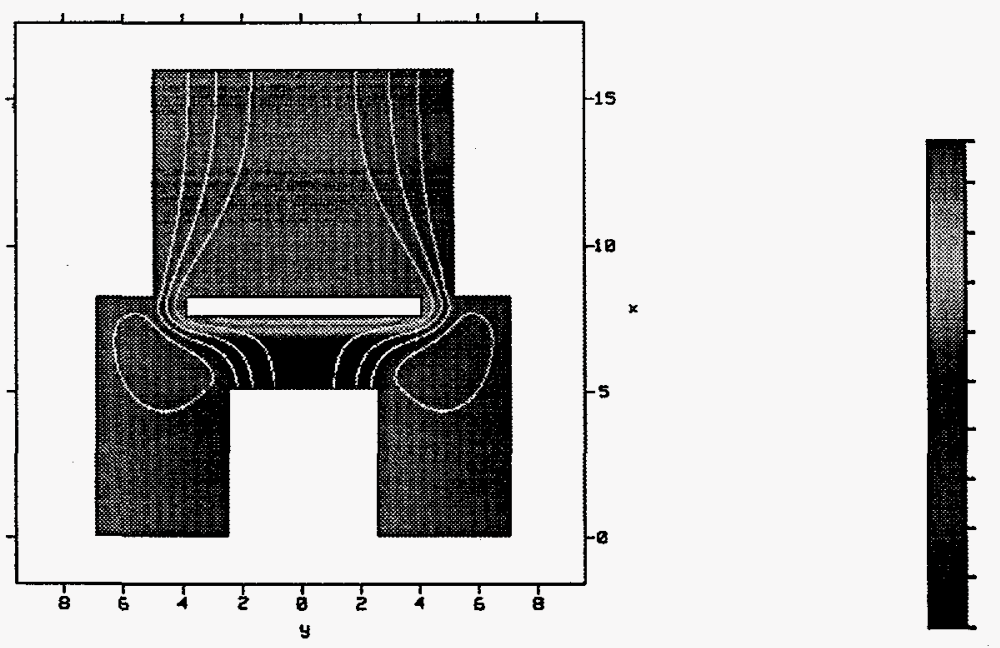

B. $73 E+82$

8. $43 E+92$

8. $07 \mathrm{E}+02$

7. $72 E+B 2$

7. 36E+B2

7. $\mathrm{QIE}+\mathrm{BZ}$

$6.65 E+122$

6. $3 D E+B Z$

5. $94 E+B 2$

$5.59 E+Q 2$

(C) $6,000 \mathrm{sccm}$

$5.23 E+02$

Figure 12. Two-dimensional simulations of the stagnation-flow reactor using CURRENT for three different total gas flow rates. Substrate temperature $=873 \mathrm{~K}$, total pressure $=$ 6.0 torr. The scale at the bottom right indicates temperature in $\mathrm{K}$; the axes on each plot indicate distance in $\mathrm{cm}$. 


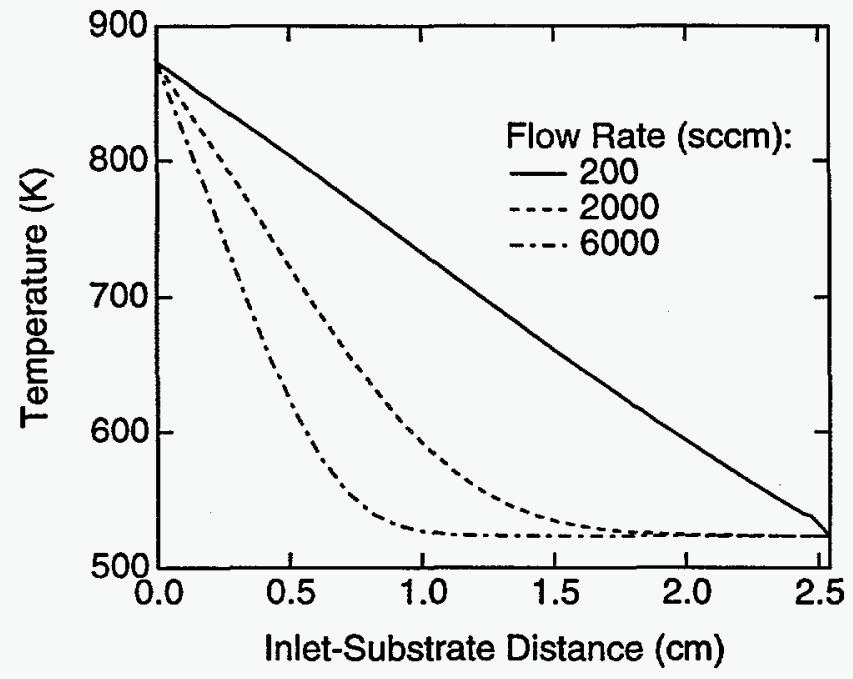

Figure 13. Centerline temperature profiles as a function of inlet-substrate distance, predicted by the CURRENT calculations.

Table IV. Comparison of thermal boundary-layer thicknesses predicted by 2D (CURRENT) calculations and non-dimensional analysis.

\begin{tabular}{|c|c|c|}
\hline Flow Rate $(\mathrm{sccm})$ & $Z_{\mathrm{bl}}(\mathrm{cm}), 2 \mathrm{D}$ model & $\begin{array}{c}Z_{\mathrm{bl}}(\mathrm{cm}), \\
\text { Non-dimen. analysis }\end{array}$ \\
\hline 200 & 2.44 & 4.50 \\
2000 & 1.40 & 1.42 \\
6000 & 0.82 & 0.82 \\
\hline
\end{tabular}

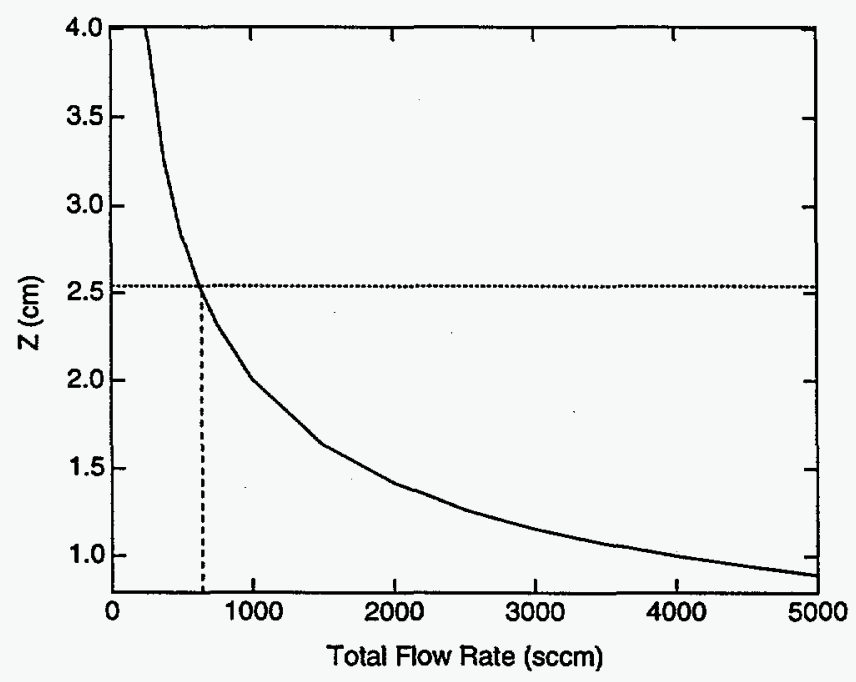

Figure 14. Dependence of boundary-layer thickness, as determined from non-dimensional analysis, on total flow rate, for the case $873 \mathrm{~K}$, nitrogen carrier gas, and substrate radius of $2.54 \mathrm{~cm}$. 
The TiN growth rate was measured in two independent ways. First, an average film thickness was determined by weighing the substrate before and after deposition. The deposition rate was then calculated by assuming that the density of the films was same as the bulk material (5.21 $\mathrm{g} / \mathrm{cm}^{3}$ ) and dividing the resulting thickness by the duration of the deposition run. Second, film thicknesses were measured directly with a profilometer. A thin silicon strip was used to mask a chord of the substrate along the centerline during deposition. Film thicknesses were then determined by measuring the difference between the masked and unmasked regions at several locations along the length of the mask. This provides a measure of the uniformity of the deposition rate across the substrate.

The resistivity of the films was measured using the four-point probe method.56 Eight random points on the film were tested, and the mean and standard deviation of the data was calculated for each films. In calculating the resistivity from the probe measurements, two key assumptions were made. First, the film thickness was assumed to be uniform; the thicknesses determined from the mass-difference measurements were used. Second, the silicon substrates were assumed to be nonconducting. These assumptions are critical in calculating the resistivity of the films and correction factors available in the literature ${ }^{56}$ were used to obtain the results reported here.

In addition to analysis of film surface composition using Auger electron spectroscopy (AES), we applied two other techniques, low-energy ion scattering (LEIS) and direct recoil spectroscopy (DRS), to obtain additional quantitative information concerning the bulk film composition. In LEIS, the energy loss of ions elastically reflected from a sample surface is used to identify the masses of the surface atoms. Using singly-charged, inert-gas ions gives a high degree of surface specificity, as their large first-ionization energies result in efficient neutralization upon scattering within the solid. Since only surviving ions are detected, the observed signal arises almost entirely from scattering events occurring at the outer atomic layer of the solid. Typically, either $\mathrm{He}^{+}$or $\mathrm{Ne}^{+}$ ions were used in our experiments. In DRS, measurements of the elastic recoil energy of surface atoms ejected from the sample are used to identify their mass. While not as surface specific as LEIS, DRS is a powerful method for detecting light impurities, such as the hydrogen isotopes, at surfaces. $\mathrm{Ne}^{+}$is well suited for DRS measurements of hydrogen since, at an observation angle of $25^{\circ}$, it is possible to resolve each hydrogen isotope. In addition, this condition permits recoil emission of $\mathrm{Ti}, \mathrm{N}$, and $\mathrm{O}$ to be measured.

AES, LEIS, and DRS experiments were performed inside a turbomolecular-pumped UHV chamber (base pressure $0.3 \times 10^{-6} \mathrm{~Pa}$ ) equipped with a low-energy ion source, an electrostatic ionenergy analyzer, and a quadrupole mass spectrometer (QMS). The gas-discharge ion source (Colutron) produces a mass-analyzed beam of $\mathrm{He}^{+}, \mathrm{Ne}^{+}$, or $\mathrm{Ar}^{+}$about $150 \mu \mathrm{m}$ in diameter at an energy of $1.000 \pm 005 \mathrm{keV}$. The beam can be steered and rastered over a $1 \mathrm{~cm}^{2}$ area. $\mathrm{Ar}^{+}$is used primarily to sputter-clean samples while $\mathrm{He}^{+}$and $\mathrm{Ne}^{+}$are used for LEIS and DRS measurements. The analyzer consists of two aluminum hemispheres with a mean radius of $50 \mathrm{~mm}$ along with associated entrance and exit optics. Ions passing through the 2-mm entrance aperture are decelerated and focused into the analyzer, which has a resolution of about $2 \mathrm{eV}$ in the fixed analyzer transmission mode at a constant pass energy of $125 \mathrm{eV}$. Transmitted ions are detected with an electron multiplier operating at a potential of about $2 \mathrm{keV}$. The analyzer is mounted on a rotating table, which allows measurements to be made at observation angles ranging from $0^{\circ}$ to $90^{\circ}$ with respect to the beam axis.

\section{B. Results}

Film characterization. TiN deposits formed in the stagnation-flow reactor are generally smooth and reflective, with a copper or bronze-purple color. In no case was the gold color characteristic of sputtered TiN obtained; this is consistent with observations of other investigators using CVD. 16 
AES spectra of the films indicate the presence of both titanium and nitrogen, although the relative amounts of each atom cannot be determined due to the overlap of the titanium and nitrogen peaks (Fig. 15). However, AES does demonstrate that the films are relatively free of chlorine ([Cl]/[Ti] $\leq$ 0.04). Oxygen is also detected on the surface; however, one hour of sputtering with $5 \mathrm{KeV}$ argon ions reduced the oxygen signal to a negligible amount, showing that the oxygen is confined to the surface and is not part of the bulk film. LEIS and DRS measurements using $3 \mathrm{KeV}$ neon ions (Fig. 16) also exhibit strong peaks from titanium and nitrogen; again, no evidence for chlorine is found. LEIS could provide a quantitative measurement of the relative amounts of $\mathrm{Ti}$ and $\mathrm{N}$ in the film, given a TiN standard. Unfortunately, no such standard exists. However, we compared LEIS spectra obtained from the CVD films with those obtained from a sample produced by laserinduced sputtering, which exhibits the highly reflective, golden color associated with stoichiometric TiN. Relative to this sample, the TiN samples produced by CVD are approximately stoichiometric, with a slight excess $(5-10 \%)$ of nitrogen at the surface. Field-emission scanning electron microscopy indicates that the films have an extremely fine-grained microstructure, with a resolvable feature size on the order of $10 \mathrm{~nm}$ (Fig. 17).

Figure 18 shows the results of four-point probe measurements of film resistivity. Resistivities ranged from $2300 \mu \mathrm{ohm}-\mathrm{cm}$ to $8600 \mu \mathrm{ohm}-\mathrm{cm}$, with fairly large standard deviations associated with the average of the eight measurements made. This relatively wide variation is in part due to non-uniformity in the films, which were assumed to be uniform in thickness, although variations in film composition may also contribute. It is apparent from Figure 18 that the resistivity increases somewhat as both reactant flow rates increase. While none of the films have resistivities approaching that of bulk TiN ( $22 \mu \mathrm{ohm}-\mathrm{cm})$, film resistivity is known to increase from the bulk value in $\mathrm{TiN}_{\mathrm{X}}$ films when $\mathrm{x}>1$ or $0<\mathrm{x}<1.57$ Thus, these results suggest that compositional changes occur in the films as the inlet gas composition is varied.

Deposition Measurements. Measurements of TiN deposition rates are shown in Figure 19 as a function of the $\mathrm{NH}_{3}$ and $\mathrm{TiCl}_{4}$ inlet mole fractions. It is evident from these figures that the trends displayed by the data are in clear agreement with the model predictions. Under the conditions of our experiments, deposition rates increase approximately linearly with inlet $\mathrm{NH}_{3}$ mole fraction. (Note that this corresponds to an intermediate concentration regime of the model, rather than to the limit described by Equation 8, in which the deposition rate is second-order in $\mathrm{NH}_{3}$ concentration. Additional calculations indicate that $\mathrm{NH}_{3}$ flow rates of $10 \mathrm{sccm}$ or less are required to reach this limit.) The experiments also show that deposition is essentially independent of the $\mathrm{TiCl}_{4}$ mole fraction. The magnitudes of the measured deposition rates are also in reasonable agreement with the predicted values, although there is significant scatter in the data. In general, the average deposition rates obtained from the measurements of mass gain (squares) are in better agreement with the model than the localized measurements made at the center of the substrate using a profilometer. In the majority of the cases, the deposition rate calculated from the profilometer measurement was 50-60\% higher than the average deposition rate. Thus, there is a significant non-uniformity across the $5.0-\mathrm{cm}$-diameter substrate. It is probable that this is caused by heat loss at the edges of the substrate, rather than to flow non-uniformities, which the simulations in Sect. V.B suggest are not present under these conditions. The proximity of the substrate edge to the unheated heater/substrate holder increases the heat loss in these locations and is thus the likely cause of the temperature non-uniformity. The results are consistent with thermocouple readings, which show an edge-to-edge variation of as much as $25 \mathrm{~K}$ in some cases. In spite of this, we conclude that the model is functioning well and that improvements in the design of the substrate holder will likely lead to even better agreement between the model and experiment. 

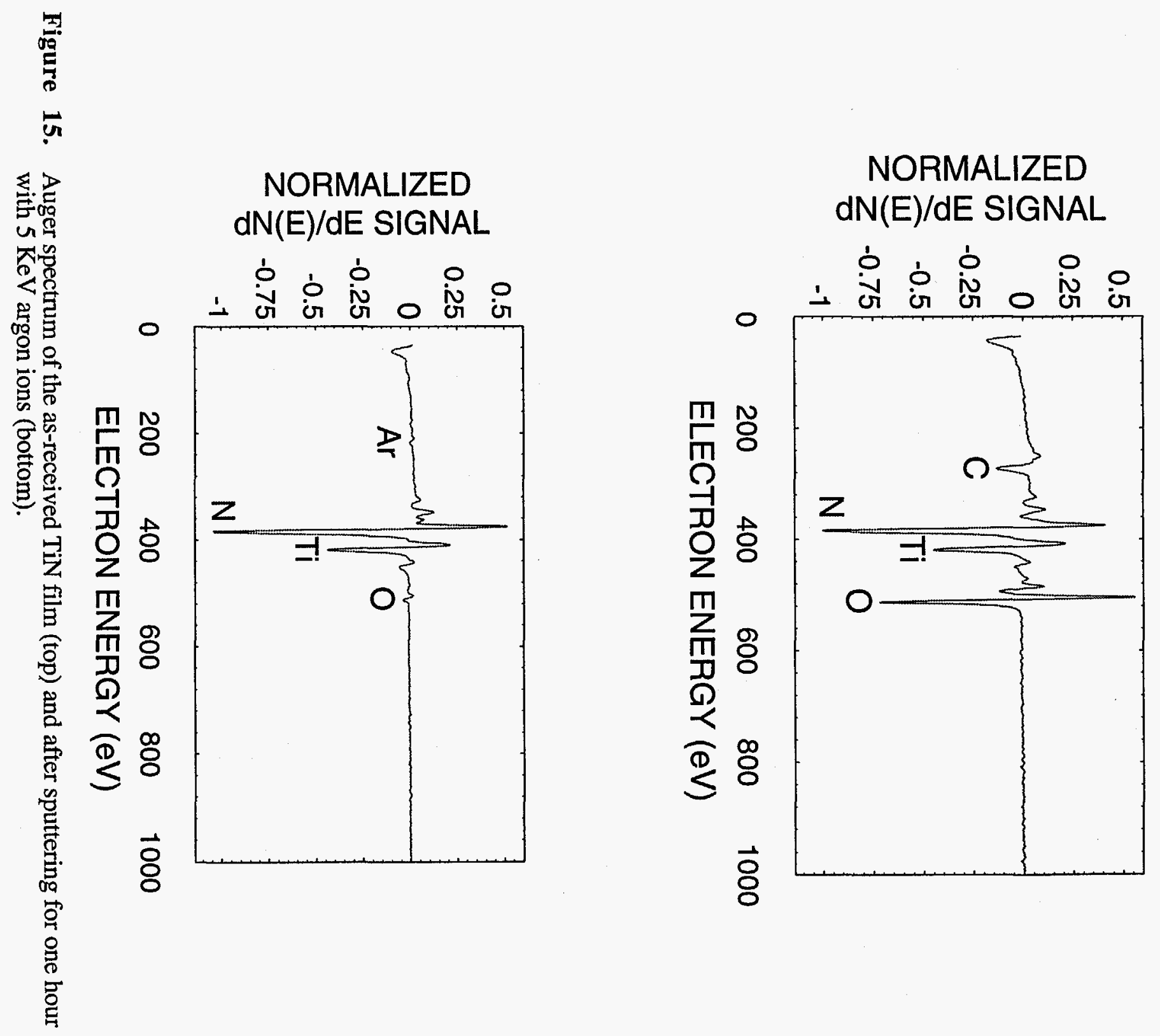


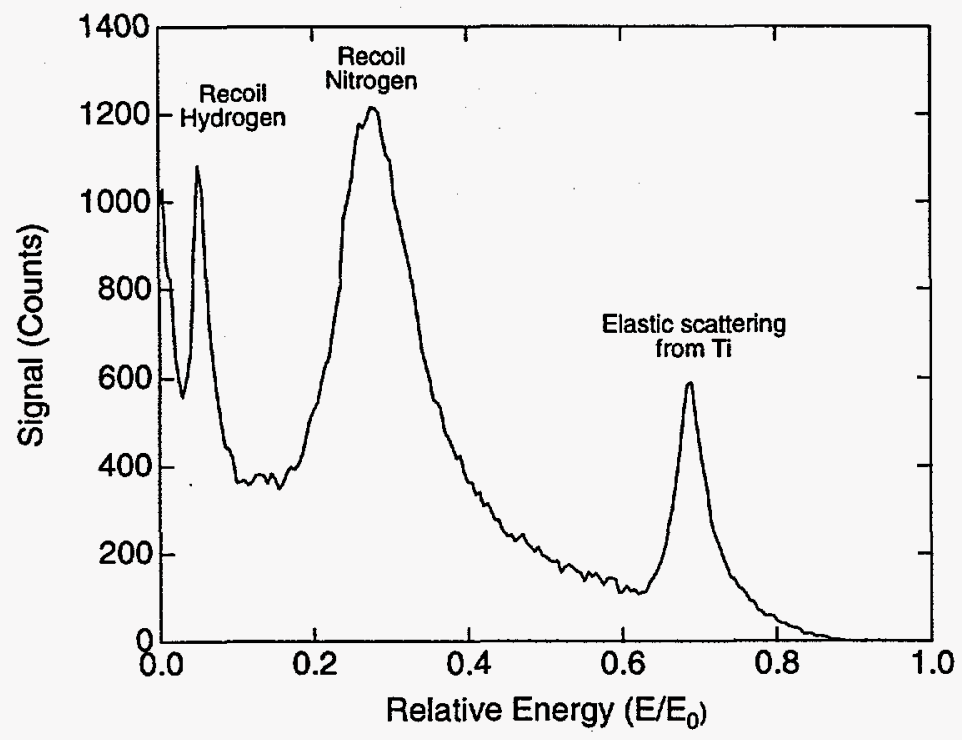

Figure 16. LEIS/DRS spectrum of a TiN film, obtained using 3-KeV neon ions.

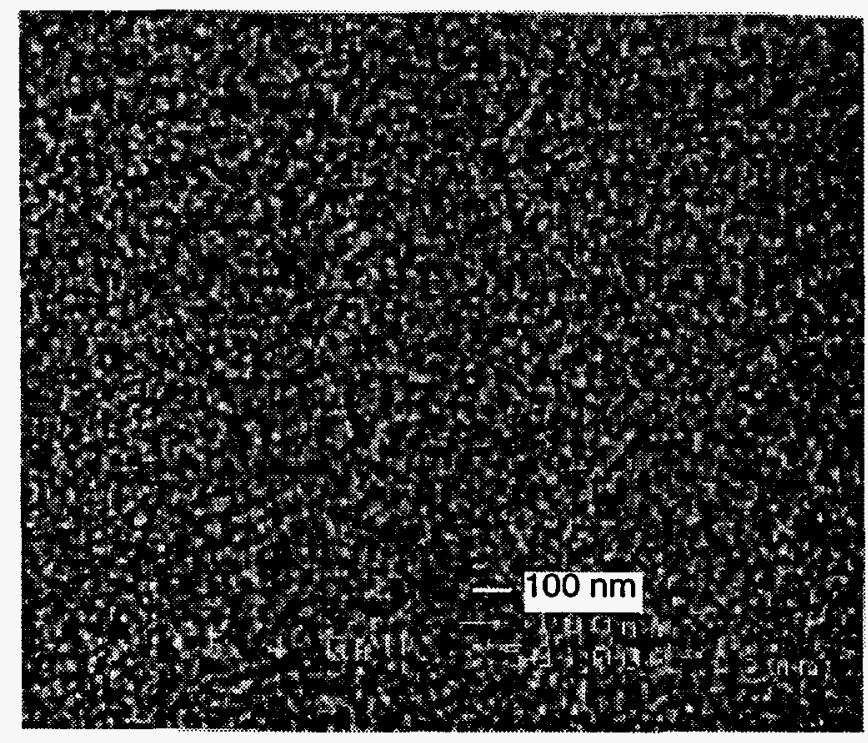

Figure 17. Field-emission SEM of typical TiN film, showing the fine-grained microstructure. 

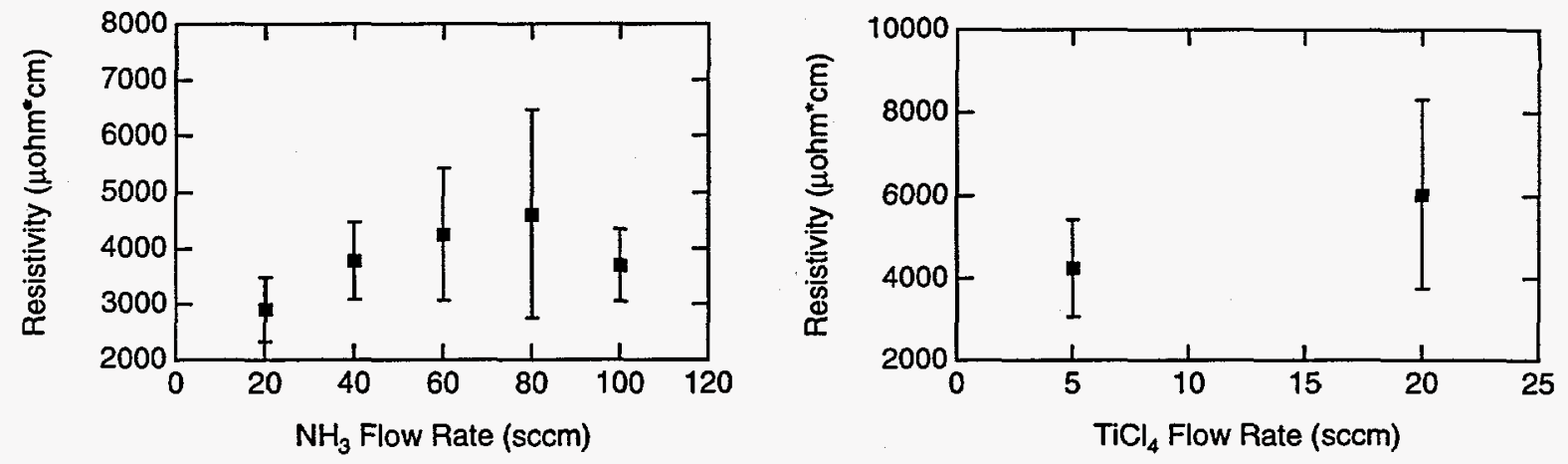

Figure 18. Four-point probe measurements of film resistivity as a function of ammonia (left) and titanium tetrachloride (right) flow rate.
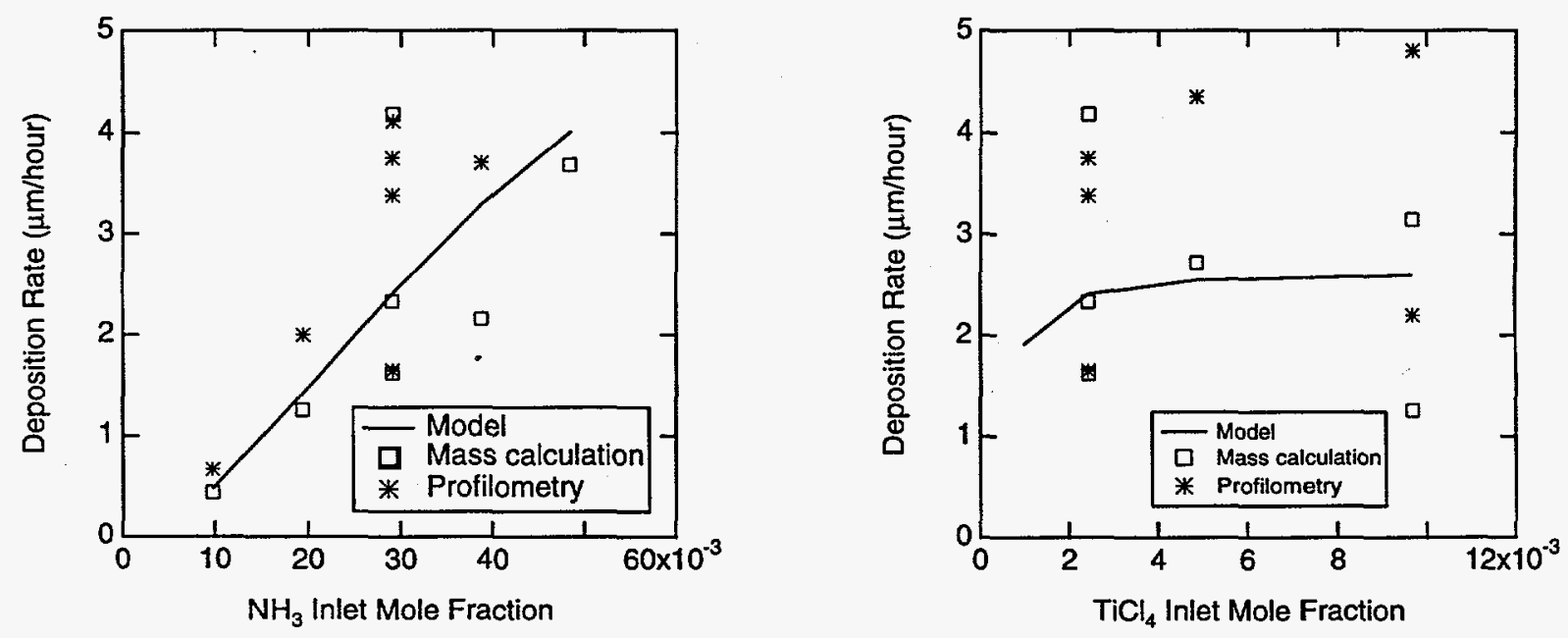

Figure 19. Dependence of the TiN deposition rate on inlet reactant $\mathrm{NH}_{3}$ (left) and $\mathrm{TiCl}_{4}$ (right) mole fractions. Deposition conditions are as described in the text. 


\section{Summary of Results and Conclusions}

In this project we developed a model that successfully predicts TiN film growth rates as a function of key reactor parameters, including inlet reactant concentrations, substrate temperatures, reactor pressures, and total gas flow rates (Sect. IV). The model was tested by comparison with the results of TiN deposition experiments in the literature and with measurements (Sect. VI) made in a new CVD reactor (Sect. V) developed for the purpose of testing deposition mechanisms such as this. The ability of the model to predict deposition rates obtained by four different sets of investigators suggests that it is reasonably robust and should thus be a useful design tool for operating TiN CVD processes using the reactants $\mathrm{TiCl}_{4}$ and $\mathrm{NH}_{3}$. Although the rate constants employed in the model are the result of fitting a complex set of equations to deposition-rate data, the predicted sticking coefficient for $\mathrm{NH}_{3}(0.01)$ is in reasonable agreement with the sticking coefficient measured by us for $\mathrm{NH}_{3}$ on TiN (0.06) (Sect. III). Thus, this suggests that the reactions used are more than an "effective" mechanism and can thus provide some insight into the nature of the actual processes occurring during deposition. Clearly, additional experimental data are required to fully test this hypothesis; in particular, it would be useful to have measurements of the temperature dependence of the deposition rate, since this could be compared with the activation energy determined from our investigation of the $\mathrm{NH}_{3}$ surface chemistry (Sect. III).

In addition to the development of the model, two other new capabilities have resulted from this research. First, $a b$ initio methods were extended for the first time to the prediction of thermodynamic properties of titanium-containing compounds (Sect. II). The results are encouraging and suggest that these methods can be used to predict missing thermodynamic data that are essential for the development of CVD models involving transition-metal compounds. Second, the new stagnation-flow CVD reactor designed and constructed as part of this project (Sect. V) provides a vehicle for obtaining data for comparison with model predictions. The availability of deposition rates measured under well characterized, controlled conditions allows deposition mechanisms to be tested and refined, leading to verified process models with great utility for the development and optimization of new CVD processes. We anticipate that both capabilities will play important roles in future research programs at Sandia.

\section{Acknowledgments}

The authors would like to thank MKS Corporation (Billerica, MA) for the generous contribution of a direct liquid injection system, without which the deposition experiments would have been impossible, and Dr. David Roberts and Dr. Robert Bryant of J. C. Schumacher (Carlsbad, CA) for their advice in handling titanium-containing precursors. Dr. Nancy Yang is also thanked for providing the SEM photographs. MDA also thanks Dr. Anthony Toprac for numerous helpful technical discussions.

\section{References}

(1) Intemann, A.; Koerner, H.; Koch, F. J. Electrochem. Soc. 1993, 140, 3215.

(2) Sherman, A. Jap. J. Appl. Phys. 1991, 30, 3553.

(3) Wittmer, M.; Melchior, H. Thin Solid Films 1982, 93, 397.

(4) Hedenqvist, P.; Olsson, M.; Wallén, P.; Kassman, A.; Hogmark, S.; Jacobson, S. Surf. Coat. Technol. 1990, 41, 243.

(5) Hegde, R. I.; Fiordalice, R. W.; Travis, E. O.; Tobin, P. J. 1993,

(6) Hillman, J.; Foster, R.; Faguet, J.; Triggs, W.; Arora, R.; Ameen, M.; Martin, F.; Arena, C. Sol. State Technol. 1995, July, 147. 
(7) Paranjpe, A.; IslamRaja, M. J. Vac. Sci. Technol. B 1995, 13, 2105.

(8) Fix, R. M.; Gordon, R. G.; Hoffman, D. M. Chem. Mater. 1991, 3, 1138.

(9) Weiller, B. H. J. Am. Chem. Soc. 1996, 118, 4975.

(10) Saeki, Y.; Matsuzaki, R.; Yajima, A.; Akiyama, M. Bull. Chem. Soc. Jpn. 1982, 55, 3193.

(11) Dresser, M. J.; Taylor, P. A.; Wallace, R. M.; Choyke, W. J.; Yates Jr., J. T. Surf. Sci. $1989,218,75$.

(12) Gland, J. L.; Kollin, E. B. J. Vac. Sci. Technol. 1981, 18, 604.

(13) Singh, N. K.; Murrell, A. J.; Foord, J. S. Surf. Sci. 1992, 274, 341.

(14) Handbook of Chemistry and Physics, 70th Ed.; Weast, R. C., Ed.; CRC Press: Boca Raton, FL, 1989.

(15) Haywood, D. O.; Trapnell, B. M. W. Chemisorption; Butterworths: London, 1964.

(16) Kurtz, S. R.; Gordon, R. G. Thin Solid Films 1986, 140, 277.

(17) Buiting, M. J.; Otterloo, A. F.; Montree, A. H. J. Electrochem. Soc. 1991, 138, 500.

(18) Ohshita, Y.; Fukagawa, W.; Kobayashi, A. J. Cryst. Growth 1995, 146, 188.

(19) Chase, M. W.; Davies, C. A.; Downey, J. R.; Frurip, D. J.; McDonald, R. A.; Szverud, A. N. J. Phys. Chem. Ref. Data 1985, 1985, 14.

(20) Hildenbrand, D. L. High Temp. Mater. Sci. 1996, 35, 151.

(21) Hehre, W. J.; Radom, L.; Schleyer, P. v. R.; Pople, J. A. Ab Initio Molecular Orbital Theory; Wiley: New York, 1986.

(22) Frisch, M. J.; Trucks, G. W.; Head-Gordon, M.; Gill, P. M. W.; Wong, M. W.; Foresman, J. B.; Johnson, B. G.; Schlegel, H. B.; Robb, M. A.; Replogle, E. S.; Gomperts, R.; Andres, J. L.; Raghavachari, K.; Binkley, J. S.; Gonzalez, C.; Martin, R. L.; Defrees, D. J.; Baker, J.; Stewart, J. J. P.; Pople, J. A. Gaussian 92, Revision B; Gaussian, Inc.: Pittsburgh, 1992.

(23) Wachters, A. J. H. J. Chem. Phys. 1970, 52, 1033.

(24) Hood, D. M.; Pitzer, R. M.; Schaeffer 3rd, H. F. J. Chem. Phys. 1979, 71, 705.

(25) Becke, A. D. Phys. Rev. A 1988, 38, 3098.

(26) Lee, C.; Yang, W.; Parr, R. A. Phys. Rev. B 1988, 37, 785.

(27) Bauschilcher Jr., C. W.; Taylor, P. R. Theoret. Chim. Acta 1993, 86, 13.

(28) Dunning Jr., T. H.; Hay, P. J. in Modern Theoretical Chemistry: Methods of Electron Structure Theory; H. F. Schaefer 3rd, Ed.; Plenum: New York, 1977; Vol. 3.

(29) Parr, R. G.; Yang, W. Density-Functional Theory of Atoms and Molecules; Oxford University Press: New York, 1989.

(30) Cueilleron, J.; Charret, M. Bull. Soc. Chim. Fr. 1956, 802.

(31) Fowles, G. W. A.; Pollard, F. H. J. Chem. Soc. 1953, 2588.

(32) Fix, R. M.; Gordon, R. G.; Hoffman, D. M. in Mater. Res. Soc. Symp. Proc. 168, 357 (1990).

(33) Prybyla, J. A.; Chiang, C.; Dubois, L. H. J. Electrochem. Soc. 1993, 140, 2695.

(34) Dubois, L. H.; Zegarski, B. R.; Girolami, G. S. J. Electrochem. Soc. 1992, 139, 3603.

(35) Weiller, B. H. in Materials Research Society: 1994; p. 379.

(36) Weiller, B. H. in Materials Research Society: 1994; p. 159.

(37) Weiller, B. H.; Partido, B. V. Chem. Mat. 1994, 6, 260.

(38) Everhart, J. B.; Ault, B. S. Inorg. Chem. 1995, 34, 4379.

(39) Antler, M.; Laubengayer, A. W. J. Am. Chem. Soc. 1955, 77, 5250.

(40) Truong, C. M.; Chen, P. J.; Corneille, J. S.; Oh, W. S.; Goodman, D. W. J. Phys. Chem. 1995, 99, 8831.

(41) Larson, R. S.; Allendorf, M. D. in Thirteenth Int. Conf. Chem. Vapor Dep.; The Electrochemical Society: Los Angeles, 1996; p. 41 (See also Sandia National Laboratories Report SAND96-8443).

(42) Allendorf, M. D.; Janssen, C. L.; Colvin, M. E.; Melius, C. F.; Nielsen, I. M. B.; Osterheld, T. H.; Ho, P. in Process Control, Diagnostics, and Modeling in Semiconductor Manufacturing; The Electrochemical Society: Reno, 1995; p. 393 (see also Sandia National Laboratories Report SAND96-8636, 1996).

(43) Schulberg, M. T.; Allendorf, M. D.; Outka, D. A. Surf. Sci. 1995, 341, 262. 
(44) Schulberg, M. T.; Allendorf, M. D.; Outka, D. A. in Covalent Ceramics III-Science and Technology of Non-Oxides; The Materials Research Society: Boston, 1995; p. 453.

(45) Schulberg, M. T.; Allendorf, M. D.; Outka, D. A: J. Vac. Sci. Technol. A 1996, 14, 1 (See also Sandia National Laboratories Report SAND96-8580, 1996).

(46) Hoch, M.; Dingledy, D. P.; Johnston, J. L. J. Amer. Chem. Soc. 1955, 77, 304.

(47) Srinivas, D.; Hillman, J. T.; Triggs, W. M.; Eichman, E. C. in Advanced Metallization for ULSI Applications/1991; Materials Research Society: Pittsburgh, PA, 1992; p. 319.

(48) Mochizuki, Y.; Okamoto, Y.; Ishitani, A.; Hirose, K.; Takada, T. Jpn. J. Appl. Phys. 1995, 34, L326.

(49) Jiang, C.; Goto, T.; Hirai, T. J. Mater. Sci. 1993, 28, 6446.

(50) Price, J. B.; Borland, J. O.; Selbrede,-S. Thin Solid Films 1993, 236, 311.

(51) Custer, J. S.; Smith, P. M., personal communication, 1995.

(52) Coltrin, M. E.; Kee, R. J.; Evans, G. H.; Meeks, E.; Rupley, F. M.; Grcar, J. F. "SPIN (Version 3.83): A Fortran Program for Modeling One-Dimensional RotatingDisk/Stagnation-Flow Chemical Vapor Deposition Reactors," Sandia National Laboratories Report SAND91-8003, 1991.

(53) von Karman, T. A. Angew. Math. Mech. 1921, 1, 233.

(54) Winters, W. S.; Evans, G. H.; Moen, C. D. "CURRENT-A Computer Code for Modeling Two-Dimensional, Chemically Reacting, Low Mach Number Flows," Sandia National Laboratories Report SAND97-8202, 1996.

(55) White, F. M. Viscous Fluid Flow; McGraw-Hill: New York, 1974, p. 172-178.

(56) Schroder, D. K. Semiconductor Material and Device Characterization; Wiley: New York, 1990.

(57) Wittmer, M.; Studer, B.; Melchior, H. J. Appl. Phys. 1981, 52, 5722. 


\section{INITIAL DISTRIBUTION}

Mr. A. Arsenlis

134 College Avenue \#3

Ithaca, NY 14850

Dr. M. L. Schulberg

Varian Associates

3075 Hansen Way, MS K-455

Palo Alto, CA 94304

MS0601 P. Ho, 1126

MS0601 J. Tsao, 1126

MS1079 A. D. Romig, 1300

MS1084 J. S. Custer, 1323

MS1084 P. M. Smith, 1323

MS9405 D. L. Lindner, 1809

MS1436 C. Meyers, 4523

MS9214 M. E. Colvin, 8117

MS9214 C. F. Melius, 8117

MS9403 J. M. Hruby, 8230

MS9054 W. J. McLean, 8300

MS9161 R. H. Stulen, 8250

MS9163 W. Bauer, 8302

MS9042 G. H. Evans, 8345

MS9053 C. M. Hartwig, 8345

MS9053 R. S. Larson, 8345

MS9057 L. A. Rahn, 8351

MS9055 F. P. Tully, 8353

MS9052 D. R. Hardesty, 8361 (3)

MS9052 M. D. Allendorf, 8361 (5)

MS9904 T. M. Dyer, 8700

MS9402 M. W. Perra, 8711

MS9403 M. Baskes, 8712

MS9403 J. C. F. Wang, 8713

MS9402 G. J. Thomas, 8715

MW9161 R. Bastasz, 8716

MS9161 K. L. Wilson, 8716

MS9161 W. G. Wolfer, 8717

MS9042 M. R. Birnbaum, 8742

MS9042 P. E. Nielan, 8743

MS9007 A. E. Pontau, 8801

MS9161 C. W. Sumpter, 8803

MS9021 Technical Communications Department, 8535, for OSTI

MS9021 Technical Communications Department, 8535/Technical Library, MS0899, 13414

MS0899 Technical Library, 13414 (4)

MS9018 Central Technical Files, 8523-2

(3) 